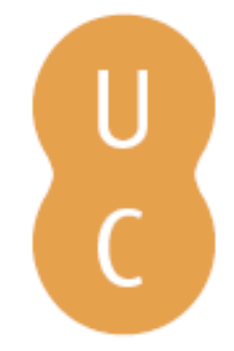

\title{
pommalina
}

\section{VETERA CHRISTIANA MONUMENTA IN BAETICA: hacia una sistematización de la arquitectura de época tardoantigua en la parte occidental de la provincia}

Autor(es): $\quad$ Sánchez Velasco, Jerónimo

Publicado por: Imprensa da Universidade de Coimbra

URL

persistente: URI:http://hdl.handle.net/10316.2/42122

DOI: $\quad$ DOI:https://doi.org/10.14195/978-989-26-1353-6_11

Accessed : $\quad$ 26-Apr-2023 14:29:36

A navegação consulta e descarregamento dos títulos inseridos nas Bibliotecas Digitais UC Digitalis, UC Pombalina e UC Impactum, pressupõem a aceitação plena e sem reservas dos Termos e Condições de Uso destas Bibliotecas Digitais, disponíveis em https://digitalis.uc.pt/pt-pt/termos.

Conforme exposto nos referidos Termos e Condições de Uso, o descarregamento de títulos de acesso restrito requer uma licença válida de autorização devendo o utilizador aceder ao(s) documento(s) a partir de um endereço de IP da instituição detentora da supramencionada licença.

Ao utilizador é apenas permitido o descarregamento para uso pessoal, pelo que o emprego do(s) título(s) descarregado(s) para outro fim, designadamente comercial, carece de autorização do respetivo autor ou editor da obra.

Na medida em que todas as obras da UC Digitalis se encontram protegidas pelo Código do Direito de Autor e Direitos Conexos e demais legislação aplicável, toda a cópia, parcial ou total, deste documento, nos casos em que é legalmente admitida, deverá conter ou fazer-se acompanhar por este aviso. 


\section{Arqueologia \\ da transição:}

entre o mundo romano

e a Idade Média

Cláudia Teixeira, André Carneiro (coords.)

IMPRENSA DA UNIVERSIDADE DE COIMBRA

ANNABLUME 


\section{VETERA CHRISTIANA MONUMENTA IN BAETICA.}

HACIA UNA SISTEMATIZACión dE LA ARQUiTECTURA DE ÉPOCA

TARDOANTIGUA EN LA PARTE OCCIDENTAL DE LA PROVINCIA (VETERA CHRISTIANA MONUMENTA IN BAETICA. Towards a late antique architecture systematization in the western part of the province)

Jerónimo SÁnchez Velasco (jeronimo.sanchez.velasco@gmail.com)

Resumo - Os edifícios de época tardoantiga que se conhecem na Bética são sistematizados, de acordo com os diferentes tipos, por forma e função. A sua datação, em muitos casos incerta, não permite adiantar dados sobre uma hipotética evolução entre os diferentes tipos de edifícios. Os monumentos de tipo funerário não são incluídos neste estudo. Palavras-chave - Arquitectura tardo-antiga, Betica, elementos arquitectónicos.

Aвstract - The Late Antique buildings known in the Baetica province are reviewed, according to their specificities, form and function. Their date is in many cases uncertain, and so we cannot presume an hypothetical evolution between the different types of buildings. Funerary buildings are not considered.

KeYwords - Late Antique architecture, Baetica, architectonical elements.

\section{INTRODUCCIÓN Y ACLARACIONES PREVIAS}

El trabajo que aquí presentamos es parte de los resultados de nuestra tesis doctoral (Sánchez Velasco 2012), aunque los mismos se presentan de forma resumida, adaptándose a las normas editoriales del siguiente volumen. Además, se analizan sólo aquellos complejos edilicios que tiene una planta mínimamente reconocible o intuida (vid. mapas).

En dicha tesis doctoral se estructuró la información sobre los complejos edilicios a partir de las provincias españolas actuales, asignándoles a cada uno de ellos una referencia específica. Esta referencia es la que aquí se usará, también por comodidad, para referirnos a cada uno de los complejos edilicios analizados: las letras mayúsculas iniciales se corresponden con la provincia actual, mientras el número es el correlativo correspondiente.

\section{Construcciones Civiles}

\subsection{Infraestructuras}

Existe muy poca documentación sobre el sistema de abastecimiento y eliminación de residuos en época tardía en las ciudades de la Bética que hemos estudiado. 


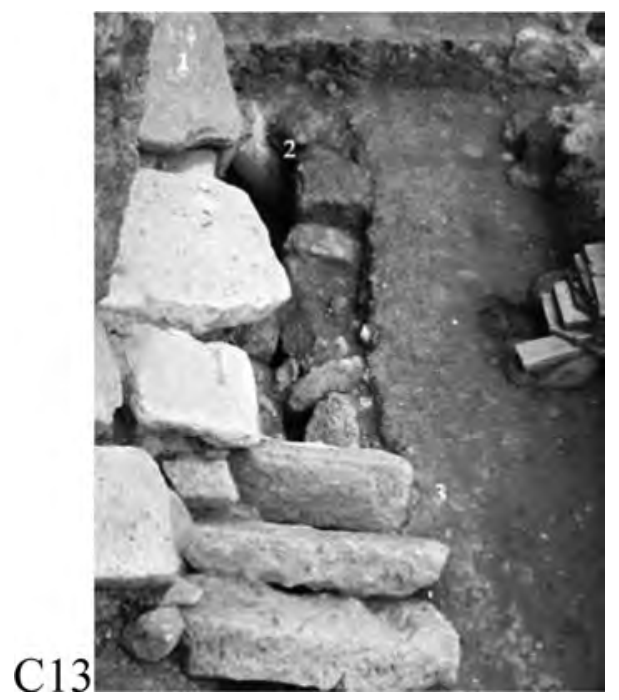

En la calle Duque de Hornachuelos de Córdoba (C13) se detectó la reparación de una cloaca, fechada en el siglo $V$ d.C., junto con la construcción del muro que, sobre ella, corta el decumano (Sánchez Velasco 2006: 196-204). El sistema empleado es el mismo que en época romana, creando un tejado a dos aguas en la reparación de la canalización, aunque en este caso se introduce parte de un fuste, y no un sillar. Siglos después, en época califal, se vuelve a reparar la cloaca, esta vez colocando tres sillares consecutivos sobre la rotura.

Resulta muy interesante comprobar cómo, durante la Antigüedad Tardía (al menos en Córdoba) se mantiene la red de alcantarillado activa, al menos en ciertos puntos donde se ha podido documentar, como ya hemos tenido la ocasión de exponer por extenso en otro lugar (Sánchez Velasco 2006; Sánchez Velasco 2011).

\subsection{Murallas y Defensas}

Tal vez, los casos que parecen más claros, a tenor de su contexto y de las excavaciones llevadas a cabo en la actualidad, son los detectados en los límites de la Pza. de la Encarnación y el hallado en el Alcázar (González Acuña 2012: 62-69). Aunque habrá que esperar a que todos estos datos se concreten a través de nuevas intervenciones.

En Italica, un supuesto muro que cruza la ampliación adrianea de la ciudad, dividiéndola en dos, y que ha sido interpretado como muralla tardía de forma acrítica (Rodríguez Hidalgo et alii, 1999: 88; Hidalgo 2003: 121-122; Diarte 2012: 169;290-292), requiere de la necesaria confirmación arqueológica (Verdugo 2003: 370ss; Sánchez Velasco 2012): primero para certificar que, efectivamente, se trata de un muro, y de carácter defensivo; segundo, para determinar su cronología. 
Para el caso de Córdoba, ya hemos expresado nuestras dudas (Ordóñez et al. 2013) sobre la entidad y cronología de ese supuesto castellum adelantado a la muralla, hallado en la zona del actual Alcázar de los Reyes Cristianos. De hecho, algunos de los restos de decoración arquitectónica que sabemos que, con total seguridad, aparecieron en las recientes excavaciones llevadas a cabo en el recinto, parecen indicar la posibilidad de la existencia de un ámbito religioso monumental, en concreto una placa-nicho (Sánchez Velasco 2012, n. ${ }^{\circ}$ cat. 175). Habrá que esperar a que nuevas intervenciones, publicadas de forma más precisa, disipen las lógicas dudas sobre unos argumentos débiles y expuestos de forma muy deficiente. Tan sólo en un caso, y dudoso, parece haberse podido datar un pequeño tramo de muralla (¿refectio? ¿ex nouo?), en la puerta oriental (López Rey 2002: 107). En las zonas de muralla que han podido ser documentadas de formas más amplia (Molina 2005; Molina-Valdivieso 2007) las reparaciones de la muralla romana parecen centrarse en el siglo iII d.C. y ya en época bajomedieval.

\subsection{Palacios - Edificios administrativos}

En teoría, todas aquellas ciudades que fueron cabeza de condado, debieron contar con centros administrativo-militares: con seguridad, Egabrum, Hispalis, Ilipla, y Corduba como capital de la provincia y sede del Dux.

De nuevo, la Arqueología se empecina en poner unos interrogantes a las afirmaciones de la tradición historiográfica. El único palacio o centro administrativo del que tenemos claras referencias (que no ubicación) a través de las fuentes, es el de Don Rodrigo, el Roderic de las fuentes árabes, que -tradicionalmente- se ha venido localizando en la zona del antiguo alcázar omeya, debido a cierta interpretación de dichas fuentes (Marfil 2000). En la actualidad, ninguna de las pruebas aportadas por la Arqueología es capaz de sustentar, de forma incuestionable, esta hipótesis y, por consiguiente, no podemos asociar ningún resto arqueológico con dichos complejos civiles de forma rigurosa.

\section{Construcciones Religiosas}

Suponen el grueso de la nómina de edificios analizados, aunque básicamente porque son más fácilmente reconocibles que el resto. Pensamos que no cabe duda de que esta descompensación se debe más a la falta de investigación que a una supuesta y apabullante hegemonía de las construcciones religiosas sobre las de otra funcionalidad. 


\subsection{Complejos Episcopales}

$\mathrm{C} 4$

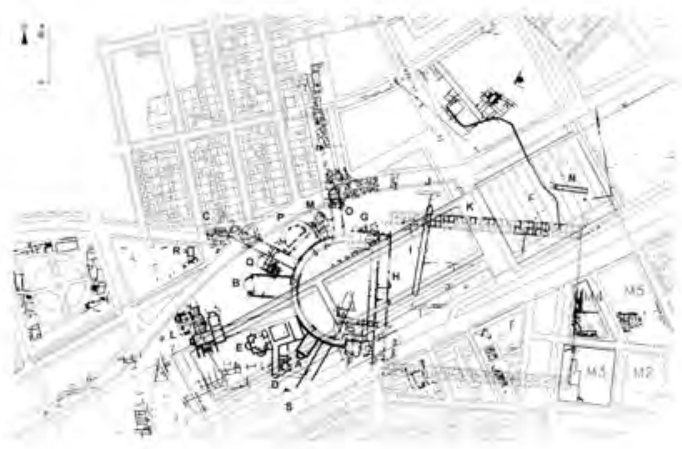

$\mathrm{C} 10$

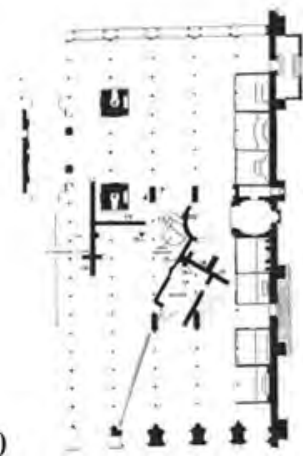

Las ciudades que fueron sedes episcopales debieron contar con un complejo de estas características, llamado por parte de la historiografía francesa "grupo episcopal" debido a que en él se aglutinan edificios muy diversos de funciones no menos heterogéneas.

En la Bética occidental, la problemática sobre los complejos episcopales es idéntica a otras zonas del Imperio, como Palaestina Prima por ejemplo (Piccirillo 1989), el conocimiento de obispos y comunidades cristianas es amplísimo pero donde no se conoce nada más que el episcopium de Jerusalén, y no sin dudas.

Nada sabemos de episcopia como los debieron existir en Ilipla, Italica o Egabrum. Sin mucho fundamento se ha supuesto que el episcopium de Hispalis estaría en la zona extramuros del Patio de Banderas ${ }^{1}$, aunque recientes hipótesis (Sánchez Velasco 2012; García Vargas 2012) lo ubican, de forma más documentada, en el entorno de la c/ Mármoles, aunque todavía debe concretarse de forma arqueológica (vid. infra).

Tan sólo en Corduba contamos con evidencias suficientes para hablar de dos grupos episcopales. Y lo decimos en plural porque mantenemos como hipótesis de trabajo, que esta ciudad pudo contar con dos núcleos episcopales diacrónicos. Uno se ubicaría extramuros, tendría una cronología muy temprana (s. Iv d.C.) y tal vez estaría relacionado con la figura del obispo Osio, consejero imperial e influyente miembro de la corte de Constantino, que podría haber influido en la realización de la primera fase de este gigantesco complejo. Ya hemos defendido en varias ocasiones (Sánchez Velasco 2011; Sánchez Velasco 2013) las razones arqueológicas que nos llevan a defender la existencia de un complejo episcopal

${ }^{1}$ Bendala; Negueruela 1980; Blanco 1989; Ristow 1998; Tarradellas Corominas 2000; Gurt; Sánchez 2008; Sánchez Ramos 2009; Gurt; Sánchez 2010; Barragán Valencia 2010; Gurt; Sánchez 2011. 
completo en Cercadilla, basadas en la falta de una lógica interpretación de la secuencia estratigráfica de las edificaciones, y por qué no puede ser considerado ni un palacio imperial ni una gran villa extraurbana. Por lo que no entraremos más en esta cuestión. Un segundo grupo episcopal, cuyo principal apoyo son las fuentes árabes y determinados restos arqueológicos, pudo ser un traslado a una zona intramuros a partir del s. vi d.C. (Ordóñez et al. 2013).

Esta línea de trabajo que mantenemos no asume como válidas las últimas tendencias historiográficas de buena parte de los especialistas actuales en la materia, que consideran que los complejos episcopales, desde época muy temprana, se ubican intramuros: en algunos casos en áreas periféricas de la ciudad; en otros, sobre los antiguos foros. La bibliografía es muy extensa, pero esta tendencia se consolida a partir del XI Congreso Internacional de Arqueología Cristiana, celebrado en Lyon (Duval 1989), donde una parte se dedica, de forma monográfica, a abordar la cuestión de los episcopia. Básicamente, se contempla lo difícil que es definir con claridad este tipo de conjuntos ${ }^{2}$, por múltiples razones: a) deben tener un baptisterio, pero no todos los baptisterios indican la presencia de complejos episcopales; b) la presencia de grandes conjuntos de edificios, relacionados entre sí y de gran monumentalidad, pueden responder a razones vinculadas al culto martirial, o a complejos monásticos; c) generalmente las residencias episcopales son edificios de gran monumentalidad unidos a basílicas, pero esta unión no tiene por qué significar necesariamente que, cuando se dan, sean episcopia; d) los obispos se suelen enterrar en estos complejos, en grandes mausoleos vinculados directamente con los edificios de culto, pero tampoco esto es definitorio, porque sabemos que muchos obispos se entierra allí donde estiman más oportuno, en muchos casos en importantes focos de culto martirial. En conclusión, la clave para definir los complejos episcopales se basó en lo que parecía una constante: su ubicación dentro de las ciudades.

Así, en un importante artículo de Testini, Pani y Cantino (1989) en el marco de dicho congreso, se determinó que, en Italia, prácticamente todos los complejos episcopales se encontraban intramuros, salvo contadas excepciones, algunas de ellas no bien atestiguadas arqueológicamente, y desde momentos muy tempranos. Incluso en los escasos ejemplos por ellos reconocidos en los que la existencia de complejos extraurbanos es difícilmente discutible, se insiste en que el suburbio próximo es, sin lugar a dudas, ciudad.

Este análisis se extiende de Italia a otros lugares, como Gallia, Turquía o África, donde los resultados serían los mismos. A partir de ahí, queda establecido, pues, que una característica importante de los conjuntos episcopales es su ubicación intramuros, dados los ejemplos estudiados. Recientes estudios que abordan

${ }^{2}$ Un ilustrativo texto sobre los problemas para definir este tipo de complejos puede verse en Duval 1989: 348-375. 
la cuestión, tanto en Gallia (Guyon 2006: 92-95) como en Hispania, inciden en esta apreciación, e incluso van más allá, al considerarlo una "norma" (Arbeiter 2010) e, incluso, un error debido a "un notable desconocimiento sobre el proceso de cristianización de la topografía cristiana de las ciudades del Imperio" (Chavarría 2010: 448).

Sin embargo, el único error evidente radica en desconocer las realidades arqueológicas locales e intentar generalizar a partir de generalizaciones previas, y siempre desde un cierto dogmatismo que busca generar una suerte de "leyes científicas” (Chavarría 2010) que, ante un análisis más sosegado, riguroso e imparcial, no se sostienen, entre otras razones porque se pretende exportar un "modelo" itálico o gálico a un territorio que, como las Hispanias, dista mucho de ser homogéneo o - siquiera - bien conocido. Esta situación de heterogeneidad ya se ha demostrado para los baptisterios hispanos (Godoy 1989: 611; nt. 14 con bibliografía sobre la cuestión), y no se ha pretendido unificar ni normativizar este tipo de restos (sobre los que, por otra parte, la investigación es escasísima, quizás por lo complejo de la cuestión).

En definitiva, las distorsiones en este esquema tan cerrado vienen de un acercamiento a las realidades locales y a los estudios de conjunto que exponen, con claridad, la situación real del conocimiento de las ciudades que contaron con un episcopium.

La primera cuestión es, sin duda, determinar la cronología de los primeros complejos episcopales, ya que la inmensa mayoría de ellos tiene fechas muy tardías, de siglo V avanzado o VI, cuando conocemos obispos, tanto en Hispania como en el resto de la zona occidental del Imperio, desde al menos el siglo III d.C. con seguridad total.

Luego, para saber si un episcopium (claramente definido como tal) está intramuros o extramuros es, obviamente, necesario conocer los perímetros amurallados de las ciudades en cuestión. En un elevadísimo porcentaje de las ciudades galas (Guyon 2006), itálicas (Testini-Pani-Cantino 1989: 89-229) o norteafricanas (Duval 1989) en las que se ha supuesto un episcopium intramuros no se conoce el recorrido preciso de la muralla y, con muchas reservas, se supone parte de la extensión de la ciudad. En casos italianos -más estudiados y numerosos- donde la cerca defensiva se conoce bien, como por ejemplo Aquileia (Bertacchi-Luigiano 2003; Cantino 1989: 182-187), Concordia Sagittaria (Cantino 1989: 190-193), Parma (Cantino 1989: 155-157), Rávena (Cantino 1989: 140-142), Florencia (Pani 1989: 122-126) o Pisa (Pani 1989: 130-132), los complejos episcopales se encuentran fuera de las murallas, en el suburbio. Recientes estudios para el sur de Italia (Sami 2010) demuestran, a través de la Arqueología y los textos, que los episcopia de Siracusa, Agrigento y, posiblemente, Taormina, estaban en los respectivos suburbia de estas ciudades, al menos hasta bien entrado el siglo vi d.C.

En el caso de Gallia (Heijmans-Guyon 2006: 94-95), el problema de las murallas persiste, aunque tan sólo se admite para el caso de Dax (Aquitania) 
una posible existencia extramuros del complejo episcopal, definido a partir de unos textos del siglo xI d.C. Aunque se reconoce que, en muchas ocasiones, de la ciudad tardoantigua apenas si se sabe de la existencia de algunos muros o edificios completos.

Hispania no es una excepción en este desconocimiento generalizado de los núcleos episcopales, lo que ha dado lugar a desafortunadas apreciaciones a favor de que la mayoría de los episcopia sean extramuros (Kulikowski 2005) o, por el contrario, intramuros (Chavarría 2010). Frente a estos extremos, se impone una lectura más sosegada y documentada, que se inclina hacia la postura historiográfica actual de establecer como paradigma la ubicación intramuros de los episcopia hispanos (Arbeiter 2010). El tema, sin duda de moda, cuenta recientemente con nuevas publicaciones, aunque más a modo de resumen de lo ya avanzado por otros que como verdadera aportación científica (Gurt-Sánchez 2011).

Con seguridad, conocemos poquísimos complejos episcopales hispanos: $\mathrm{Va}$ lentia (Ribera 2008), Egara (García; Moro; Tuset 2009) y Barcino (Arbeiter 2010). El primero es de la segunda mitad del siglo v d.C. y está situado en pleno foro de la vieja ciudad romana; del segundo no se conoce la ubicación de la ciudad romana y, bajo el episcopium creado ex nouo en el siglo v d.C., no se han encontrado restos anteriores; el tercero se ubica en una zona periférica. Como se puede apreciar, tres conjuntos, tres ubicaciones diferentes. A éstos habría que sumar, como presumibles, varios casos más. Complutum, donde una memoria a los santos Justo y Pastor pasaría a ser la catedral de la ciudad, extramuros (Rascón; Sánchez 2008: 255-257). Egitania, donde bajo la catedral actual, intramuros de la ciudad antigua, hay un baptisterio tardoantiguo, lo que ha hecho pensar sin dudas que sería parte del episcopium (Arbeiter 2010: 423). En un caso parecido a Egitania estaría Ampurias, donde el hallazgo de una piscina bautismal extramuros, en Santa Margarida, ha sido interpretado como indicio de un posible episcopium (Nolla 1993), algo visto con mucho escepticismo por algunos investigadores (Arbeiter 2010: 424). Segobriga, en cuyo impresionante complejo extramuros hay enterrados varios obispos, ha sido considerado el conjunto episcopal por parte de la investigación alemana (Schlunk; Hauschild 1978: 43), aunque otra parte parece descartarlo (Arbeiter 2010: 429). Para Mérida, así como para Gerona, sólo contamos con sendas fuentes textuales, del siglo vi y de época Carolingia respectivamente (Arbeiter 2010: 423; 429), que ubicarían la sede emeritense intramuros y la gerundense en el suburbio. En el caso de Tarragona, ciudad cuyas similitudes con Córdoba son extraordinariamente interesantes, es fiel reflejo de este intenso debate, con dos posturas bien argumentadas a partir de un sólido conocimiento científico de la ciudad, y que proponen una ubicación intramuros (López Vilar 2006: 257-259) frente a otra extramuros (Macías 2000). Las recientes campañas arqueológicas llevadas a cabo bajo la actual catedral tarraconense están motivadas, entre otros muchos objetivos, por la búsqueda de posibles restos del primitivo episcopium. Habrá 
que esperar a la publicación de los resultados de la segunda campaña de excavación en el interior de la catedral ${ }^{3}$ para ver clarificado el panorama. Aunque, tal vez, la presencia de un magnífico propileo tardoantiguo en torno a la plaza del Rovellat esté indicando, al igual que en Valencia (y creemos que en Sevilla, vid. infra), la delimitación de un episcopium que se situaría en una ubicación más periférica que la supuesta hasta ahora, junto al flanco nororiental de la ciudad alta.

Volviendo al tema en cuestión, creemos que en el estado actual del conocimiento, no es aconsejable establecer ninguna "norma" de ubicación, ya sea extramuros o intramuros, porque se puede caer en un dogmatismo que nada tiene que ver con la evidencia arqueológica. Pensamos que un mismo argumento para definir un episcopium no puede ser válido o inválido dependiendo de si estamos en una situación plenamente urbana o suburbana, máxime teniendo en cuenta que hay ejemplos perfectamente documentados (vid. supra) de existencia de episcopia extramuros. Conclusión: al igual que se ha determinado para otros argumentos, la ubicación intramuros no es, per se, ni un argumento incuestionable ni determinante.

Resulta evidente que la gran mayoría de los episcopia documentados se encuentran (lógicamente) dentro de las murallas de las ciudades tardoantiguas, entre otras razones porque los casos que hay atestiguados son básicamente del siglo vi d.C., o poco anterior, lo que dificulta sobremanera la comprensión de las ciudades de los siglos iv y v d.C. Y la variable "tiempo" en esta ecuación es fundamental. No podemos aplicar modelos urbanísticos del siglo vi d.C. de Italia o Francia a la ciudades romanas del siglo iv d.C. de Hispania, África o Asia, como tampoco podemos suponer grandes y radicales transformaciones en unas ciudades de la cuarta centuria donde el Cristianismo todavía era visto con enormes recelos, o directamente con abierta hostilidad. En este sentido, creemos que sigue siendo muy válida la visión de Krautheimer sobre las ciudades y capitales del Imperio en el siglo Iv d.C. (Krautheimer 2002), donde las dinámicas se vuelven heterogéneas, ricas y locales, dependiendo de multitud de factores: financiación imperial de grandes obras (Constantinopla, Jerusalén); realización de grandes complejos cristianos en un difícil equilibrio con el poder de la aristocracia pagana (Roma); importancia y patronazgo de grandes obispos, encabezando a una nueva aristocracia cristiana (Milán)... Frente a esta visión comedida de la expresión monumental del Cristianismo, está otra, la actualmente más extendida, donde se apuesta por una visibilización más radical del Cristianismo a través de grandes complejos que ocupan buena parte de las viejas ciudades paganas, desde fechas muy tempranas del siglo IV d.C., para lo que no tenemos constancia arqueológica, más bien un posicionamiento historiográfico diverso a la opinión del insigne

\footnotetext{
${ }^{3}$ Se puede ver alguna noticia sobre la cuestión en la web www.icac.net
} 
investigador alemán, hegemónica durante gran parte de la segunda mitad del siglo xx. Sin duda, la clave es el conocimiento - más que deficiente - de las ciudades de los siglos iv y $\mathrm{v}$ d.C.

\subsection{Iglesias}

La parquedad de los datos a la hora de enfrentarnos a este tipo de edificaciones nos limita radicalmente la posibilidad de establecer una tipología clara, que determine la relación entre tipos de planta, cronología y función. Por consiguiente, hemos optado por realizar una síntesis centrada en la morfología de las escasas iglesias que conocemos, sugiriendo una posible función en cada caso.

\subsubsection{Planta cuadrangular}

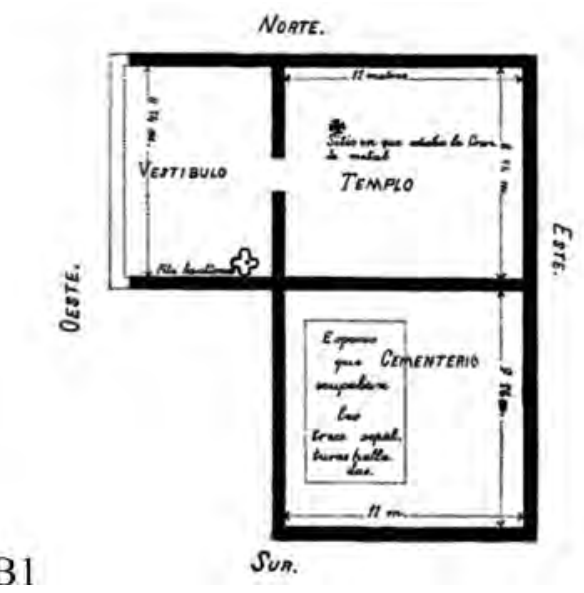

Sería el tipo arquitectónico más simple de iglesia, limitada a una sala cuadra$\mathrm{da}$ con diferentes añadidos, como son baptisterio y recinto funerario. Pensamos, a modo de hipótesis, que es posible que este tipo tan simple de edificio se corresponda con el tipo de denominación que se aplica a algunas iglesias rurales, como la que aparece en la inscripción CIL II ${ }^{2}$ / 7, 124, procedente de Porcuna, y donde se consagra una pequeña iglesia (cella) rural. Su carácter eminentemente rural nos lleva a suponer que estamos ante una iglesia relacionada con una gran propiedad, donde un pequeño templo sirve como parroquia y, sobre todo, como iglesia funeraria de la familia de los possesores, que se enterrarían ad sanctos en el recinto hallado al sur. En este sentido, otra inscripción, hallada cerca de Ategua, ilustra como uno de estos grandes propietarios debió construirse una iglesia para ser enterrado en ella (CIL II $\left.{ }^{2} / 5,482\right)$.

Este tipo de parroquias suelen estar relativamente cerca de la villa o núcleo de población rural, como puede verse en Mola di Monte Gelato (Kinney 2010: 88). 


\subsubsection{Planta rectangular}

S1
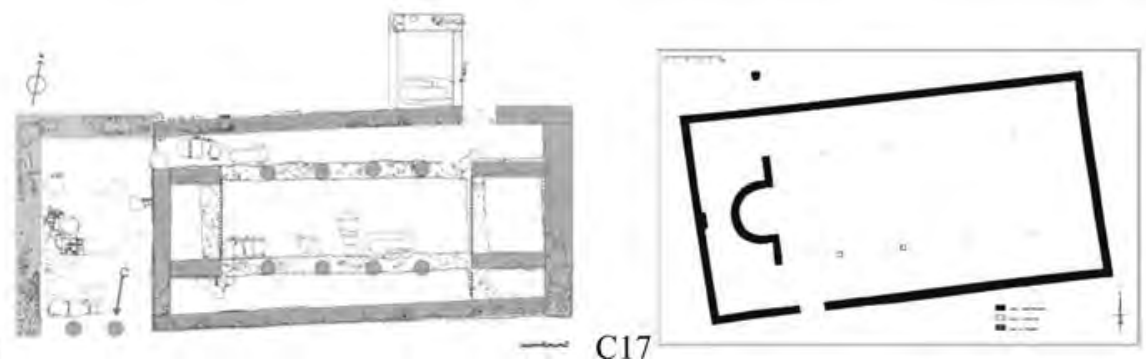

Se trata de un tipo de planta bastante bien documentado, donde los edificios tiene una forma exterior muy compacta, y en el interior es donde se desarrollan las diferentes subdivisiones litúrgicas y funcionales. En este sentido, hay amplios paralelos en todo el Mediterráneo Occidental, desde la catedral de Aquileia hasta varias iglesias baleares (Sa Carrotja, Son Fadrinet o Son Bou, vid. Alcaide 2010), pasando por Jordania (como la iglesia 20 de Umm al-Quttayn, la iglesia doble de Sabhah, vid. Michel 2001) o por multitud de ejemplos norteafricanos (en Orléansville, Tebessa, Bulla Regia, Sétif...vid. Duval 1973) todos ellos a lo largo de los cuatro siglos que nos ocupan.

Arquitectónicamente hablando, son edificios sencillos que buscan un importante ahorro de material y un proyecto más simple que la ejecución de un ábside saliente, adosandolo a alguno de los muros. Como vemos en la Gerena o en la Fase 3 de Coracho, el ábside se suele realizar con un par de muros perpendiculares al de fachada, lo que incide de nuevo en la idea de la economía de recursos. Por esto, cuando se realiza un templo de estas características con un ábside inscrito en la nave central y aislado del resto de la construcción, como el caso de Coracho (C17), debe interpretarse como una instalación litúrgica con una función precisa y realizada ex profeso, más que como un recurso estético u otro tipo de solución.

En el caso de la iglesia de Morón, como ya hemos explicado (S4) las dudas sobre si se trata de una iglesia de este tipo, de cabecera triple o absidada con anexos laterales. En cualquiera de los tres casos, lo cierto es que la forma de realizar su ábside, enmarcado en una habitación cuadrada, sería similar a lo que se supone sería la cabecera del maltratado templo de la Santa Croce de Rávena, fechado en el siglo V (Krautheimer 1996: 214-215; Jäggi 2010: 156-157) y, sobre todo, a las iglesias sirio-palestinas, como la catedral de Sergiopolis (Ulber 1989: 445ss), San Pablo en Umm al-Rasas, San Jorge en Khirbat al-Mukhayyat o la capilla de Khirbat al-Kursi (Michel 2001). 


\subsubsection{Planta absidada - basilical}

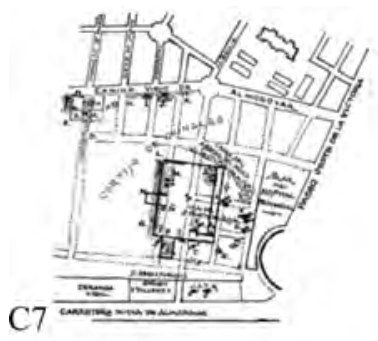

¿C6?

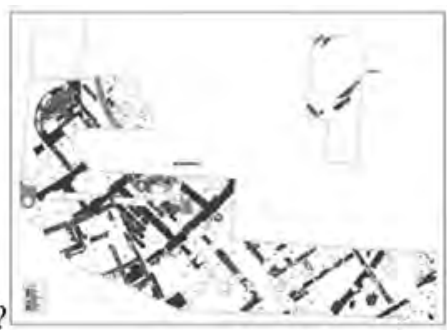

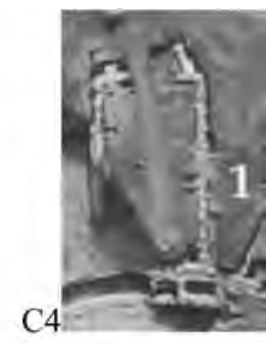

C14

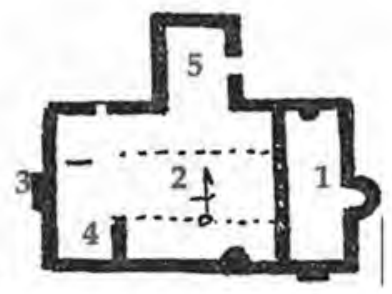

$\mathrm{B} 2$

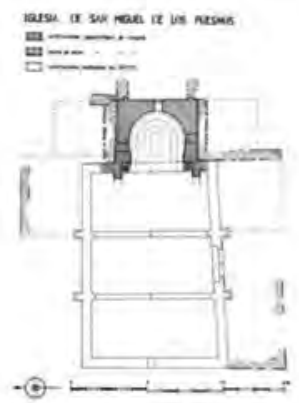

S6

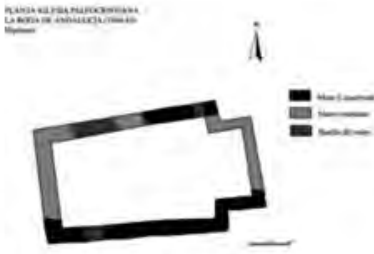

Sería, con mucho, el tipo de planta más frecuente. Y usamos el condicional porque, en realidad, los datos arqueológicos apenas si dejan entrever un par de casos posibles: Cercadilla (C4) y las - supuestas - cellae halladas en el anfiteatro occidental de Córdoba (C6), en ambos casos, posiblemente del siglo IV d.C., orientadas a Occidente y con funciones tan diversas como una gran basílica de un posible conjunto episcopal o una pequeña cellae memoriae martirial.

También con idénticas características (fecha, orientación), aunque con el ábside cuadrangular, estaría el complejo edilicio de Cortijo de Chinales (C7). Pero este extremo debe comprobarse arqueológicamente, al igual que su posible adscripción a un culto martirial.

Sin solución de continuidad, los siguientes ejemplos de planta basilical habría que buscarlos ya en el siglo VII d.C., donde encontraríamos tres ejemplos. El primero, de ábside cuadrangular, que se daría en una pequeña iglesia rural asociada a una villa (La Roda, vid. S6). El segundo, un ábside cuadrangular al exterior y con planta de arco peraltado al interior, en la gran iglesia - posiblemente - monacal y abovedada de San Miguel de los Fresnos (vid. B2), muy similar a Son 
Bou (Godoy 1995; Alcaide 2011), a Ampurias o a la iglesia de Villa Fortunatus (Schlunk-Hauschil 1978: 161-162). El tercer caso de esta fase más tardía sería la iglesia de Los Llanos (vid. C14), con un pequeño ábside semicircular, en una estructura en su cabecera que recuerda a la de la basílica de Cabeza de Griego, en Segobriga (Schlunk; Hauschild 1978: 43, fig. 21).

\subsubsection{Doble ábside}

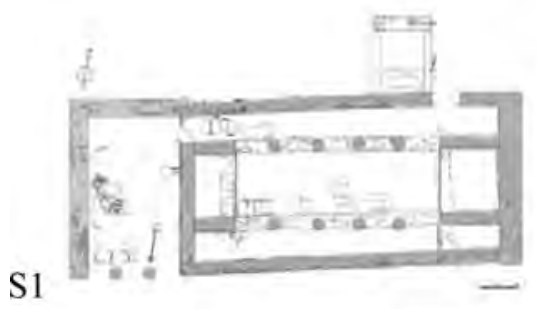

$\mathrm{C} 17$

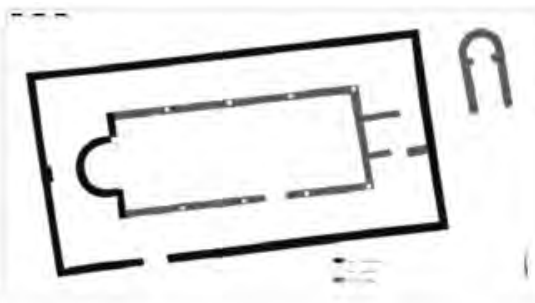

C3

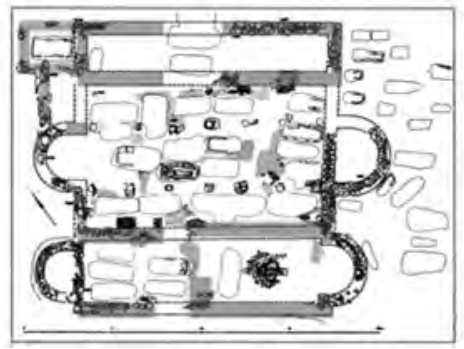

Contamos con tres ejemplos de basílicas de doble ábside y, de nuevo (amenazando con convertirse en una irritante tradición para la investigación arqueológica más normativista), cada uno respondería a subtipos diferentes. Con seguridad total nos encontramos con El Germo (C3) y con la Fase 3 de Coracho (C17). Menos seguro, pero pensamos que altamente probable, sería Gerena (S1). El primer caso, con doble ábside semicircular externo; el segundo con dos ábside inscritos, uno semicircular y otro rectangular; el tercero tendría dos ábside inscritos cuadrangulares. No entraremos aquí en avivar la intensa polémica científica entre diversos sectores de la investigación sobre la entidad litúrgica ${ }^{4}$ o la nomenclatura ${ }^{5}$ de estos edificios, y en concreto de estos ábsides, entre otras razones porque no existen en la Bética occidental elementos de juicio para ello, ya que no se han conservado instalaciones litúrgicas capaces de definir los usos religiosos concretos

\footnotetext{
${ }^{4}$ Esta polémica se aprecia con claridad (y con una acritud poco frecuente, sea dicho de paso) en las opiniones expresadas por Godoy (1995) y, en su contra, por Duval (2000).

${ }^{5}$ Creemos que la denominación de contra-ábside cuando esta estructura sobresale y de contra-coro cuando no lo hace es un tanto artificial y fruto más de una problemática historiográfica que de una realidad material evidente, al menos en la Bética occidental.
} 
con claridad. Por lo tanto, resulta a nuestro juicio algo estéril tratar de buscar, en los restos que tenemos conservados de estas basílica, un reflejo (por mínimo que sea) de aquellas prescripciones litúrgicas que aparecen en los textos.

Tan sólo en un caso contamos con dos evidencias arqueológicas que puedan dar lugar a una interpretación litúrgica: se trata del ábside occidental de Coracho. Ya hemos publicado, de forma divulgativa (Botella; Sánchez 2008) y más específicamente científica (Sánchez; Moreno; Gómez 2009), nuestra hipótesis sobre esta interesante iglesia lucentina, por lo que no nos reiteraremos. Pero sí queremos insistir en dos de los aspectos que más controversia han creado a raíz de la presentación de estos restos ${ }^{6}$ el carácter martirial y la cronología de su Fase 1; y el posible synthronon de la Fase 2. A diferencia de otras iglesias (no sólo de doble ábside), en Coracho se realizó un importante esfuerzo por determinar no tanto aspectos de carácter litúrgico y/o artístico, sino puramente arqueológicos, a partir de los cuales establecer una evolución del edificio. Por desgracia, esto es algo poco común, y la mayoría de los investigadores centrados en las interpretaciones "liturgistas" atienden poco a este tipo de cuestiones, algo más prosaicas. Para Coracho es evidente, tras un análisis arqueológico de los restos, que el edificio contó con una primera fase muy homogénea donde se realizó un ábside occidentalizado en forma de omega y separado de la fachada oeste del edificio en una anchura superior a las naves laterales. Su cronología, imposible de certificar debido a las condiciones en las que se realizó la intervención arqueológica, se ha supuesto a partir de los pocos restos cerámicos de algunas de las tumbas de inhumación que amortizan una necrópolis de cremación pagana preexistente, dando una fecha aproximada del siglo iv d.C. Con estos elementos de juicio, y teniendo presente que las iglesias son edificios funcionales realizados para albergar, a modo de escenario, la liturgia, hemos supuesto que el espacio entre la fachada oeste y el ábside en omega debió servir como ámbito de circulación (deambulatorio, muy relacionado con el tradicional culto a los muertos, vid. Krautheimer 1996: 60), con una posible finalidad martirial, con ejemplos desde el siglo IV al vi, como ya hemos visto (vid. C17).

De entrada, y para cierto sector de la investigación actual, no se puede admitir la presencia de culto martirial en determinados templos por su morfología o sus características, sin una expresa referencia textual o epigráfica que así lo indique. Además, suponer la existencia de una arquitectura monumental cristiana en el siglo iv d.C. fuera de Italia se desestima, debido a que este territorio, así como el sur de Francia, serían los lugares de más pronta e intensa cristianización. Ni que decir tiene que sus defensores son, en su mayo-

\footnotetext{
${ }^{6}$ Lo relativamente reciente de la publicación de la basílica nos hace referirnos a aspectos destacados en aquellos congresos y coloquios en los que hemos participado, donde destacados especialistas han aportado su visión sobre estos restos. Nosotros aportamos aquí un breve resumen de nuestras impresiones, esperando ver pronto, publicadas, las distintas opiniones sobre este monumento.
} 
ría, investigadores italianos y franceses que cuentan con una nómina de fuentes históricas de increíble precisión, como el Liber Pontificalis para Roma, que convierten la obtención de datos arqueológicos más en un trámite de certificación a lo dicho por los textos que en una auténtica fuente de datos. En este caso concreto de Coracho, parece evidente que la composición de los dobles ábsides responde a momentos diferentes, y no a un plan unívoco del edificio, con un primer momento de posible culto martirial focalizado en un ábside occidental que, posteriormente, se monumentaliza en una segunda fase y termina generando una basílica de doble ábside en su última reforma.

Será la entidad de esa segunda fase la que plantee más problemas, por parte de otro sector de la investigación, ya que no se admite como posible su interpretación como un esquema de arco triunfal con un posible synthronon. Los motivos se retroalimentan en un círculo sin salida: el rebanco hallado junto al ábside no puede ser un synthronon porque se trata de una instalación litúrgica ajena a culto hispano y típica del mundo bizantino; como las posesiones bizantinas se limitan a la costa mediterránea es imposible que hayan expandido su influencia hasta Lucena, por tanto no se puede hablar de synthronon (Vizcaíno Sánchez 2009: 451). Sin embargo, no se aporta ninguna solución basada en los propios restos arqueológicos que, como se puede observar, son bastante explícitos. A todo ello se suma una supuesta falta de paralelos aducibles a la construcción de un synthronon en un ábside occidental. Pero un sencillo recorrido por la bibliografía más habitual en los repertorios de iglesias de doble ábside ${ }^{7}$ arroja la nómina de analogías de este tipo de instalaciones litúrgicas en ábsides occidentalizados: basílica II de Mactar (Duval 1973: 113, fig. 60); basílica vi de Sbeitla (Duval 1973: 180, fig. 107); basílica de Henchir Goraat ez Zid (Duval 1973: 271, fig. 153); catedral de Cyrene (Duval 1973: 288, fig. 162)... Estamos trabajando en una síntesis sobre este tipo arquitectónico, y esperamos pronto aportar algunas novedades más sobre estas singulares iglesias.

\subsubsection{De Planta Central}

Un único ejemplo, dentro del complejo de Cercadilla (C4), se correspondería con esta tipología. Se trataría de un edificio E, y apenas si tenemos información del mismo. Lo que sí parece claro es que se accedería a él a través de un atrio, desde el criptopórtico. A tenor de la documentación fotográfica y de la consulta de los respectivos expedientes de excavación, se puede deducir que el edificio tuvo dos fases, ambas de planta central: primero con tres ábsides y una entrada, al este, en forma de nártex; luego, tras una destrucción que debió ser importante, se reconstruyó más pequeño, con lo que parecen cuatro ábsides cuadrangulares.

\footnotetext{
${ }^{7}$ Resulta un tanto desolador que, a pesar de la gran cantidad de novedades, tesis y proyectos de investigación existentes en torno a la arquitectura de la Antigüedad Tardía, todavía no exista ningún repertorio general unificado de este tipo de templos.
} 


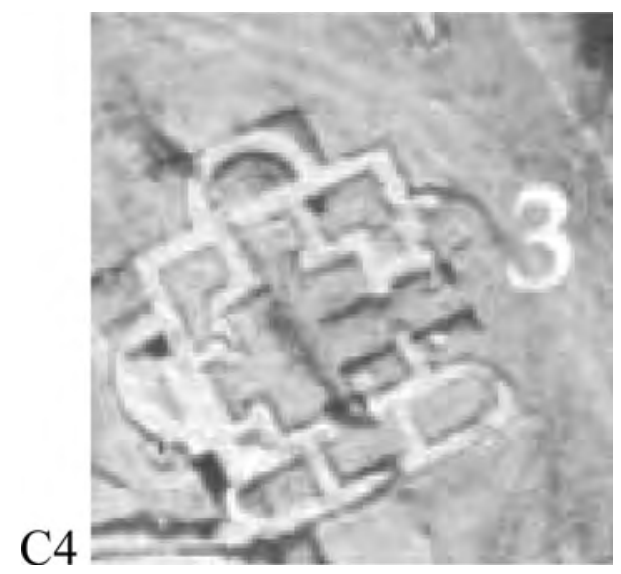

Resulta muy complicado pronunciarse sobre la función de un edificio sólo por su planta, y más en este caso. Sólo podemos decir que este tipo de edificios de planta central suelen corresponderse con funciones de conmemoración martirial o baptisterios. A los ejemplos ya aducidos sobre el tipo y la presencia de un nártex como entrada (vid. C4) habría que sumar otros ejemplos de planta central, como el edificio funerario de Sant Miquel de Egara (García; Moro; Tuset 2009: 127ss), o algunos de los grandes mausoleos anexos a las basílicas cruciformes romanas, como serían los casos de San Sebastiano o San Lorenzo. Sin embargo, este tipo de planta presente en el edificio $\mathrm{E}$ de Cercadilla (o derivados directos de la mis$\mathrm{ma}$ ), es habitual en las iglesias tardoantiguas del Illiricum oriental, como se puede ver en la iglesia E de Iustiniana Prima y sus homólogas regionales de Kursumlija o Nis (Duval 1984: 446ss). Este tipo de grandes edificios funerarios, independientemente de su planta, y que actúan como iglesias funerarias, se encuentran de forma habitual en los complejos episcopales (como el de Egara o Valentia, vid. Ribera 2009) y en los centros martiriales, como San Felice en Cimitile-Nola (Bertelli 2010: 197-201). Con todo, uno de los edificios que más se asemeja al que nos ocupa es el edificio bautismal de Gravedona I (Ristow 1998: n. 316).

\subsubsection{Triconques - Tetraconques}

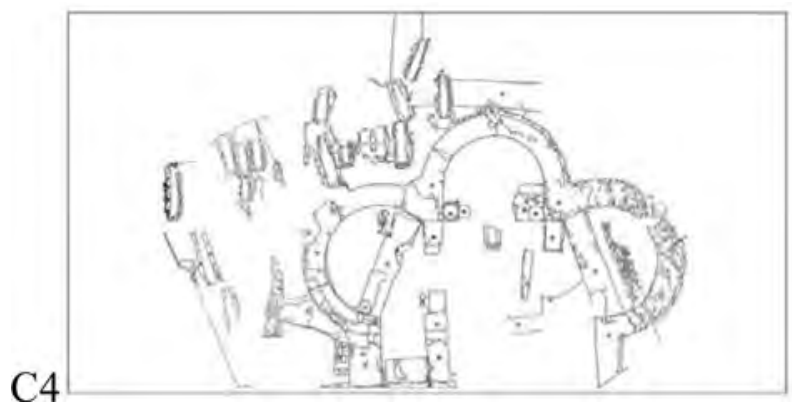


De nuevo Cercadilla (C4) vuelve a aportar el único ejemplo seguro de edificio triconque en la Bética Occidental. Nuestra hipótesis sobre La Vegueta (S11) implicaría la existencia de otro edificio de estas características, aunque habría que esperar a una confirmación arqueológica. La articulación de la cabecera triconque es muy habitual tanto en edificios funerarios como en iglesias. Que son plantas polivalentes y, diríase, multifuncionales, se puede apreciar en un único lugar, como Egara (Fig. 1), donde tanto la cripta ubicada bajo el ábside del edificio funerario como su iglesia parroquial tienen esta forma (García; Moro; Tuset 2009: 135; 145ss). Gracias a la excelente conservación de la iglesia parroquial egerense podemos hacernos una clara idea de cómo sería el alzado del edificio cordobés. En torno a ambas estructuras se han documentado gran cantidad de enterramientos, sin necesidad de que sean considerados expresión de una tumulatio ad sanctos, algo que sí se ha hecho para el edificio $G$ de Cercadilla (Sánchez Ramos 2007: 202-203).
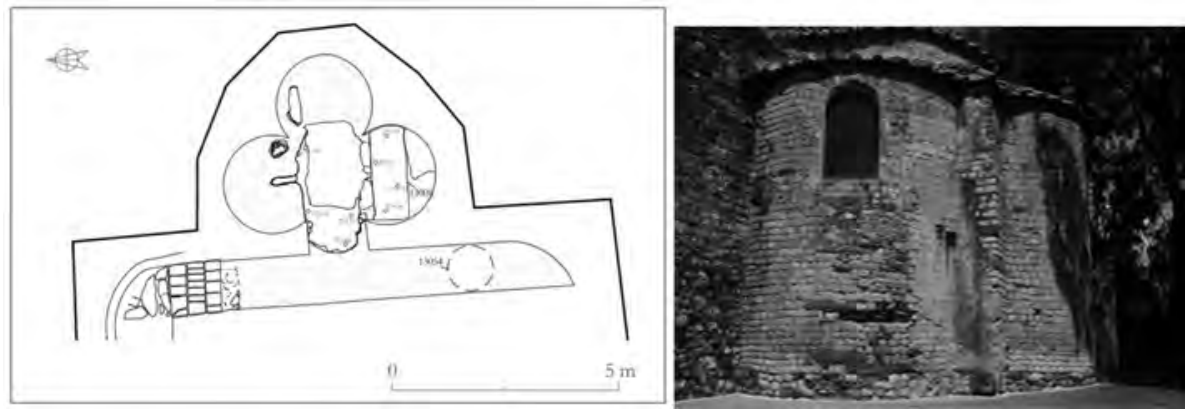

Figura 1 - Planta de Sant Miquel (izq.) y exterior de la actual parroquia (der.), antiguos edificios del episcopium de Egara.

En la cuenca Mediterránea, los ejemplos son numerosísimos, a lo largo de todo el periodo tardoantiguo, tanto para iglesias como para edificios específicamente funerarios o martyria, y han sido profusamente estudiados desde época de Grabar (1946). En Italia contamos con buenos ejemplos fechados en torno al siglo V en Cimitile-Nola o para el vi en Copanello (Bertelli 2010). En el norte de África los ejemplos de este tipo de edificios asociados a martyria fueron estudiados por Cintas y Duval (1976: 897ss) con motivo de un análisis monográfico del importante edificio hallado en Cincari. Otra zona donde iglesias y centros de conmemoración martirial cuentan con esta específica formación, insistimos, con una cronología muy dilatada, es el Illirycum, con numerosos ejemplos (Varalis 1999; Duval 1984). 


\subsection{Edificios Bautismales}

\subsubsection{Edificios complejos}
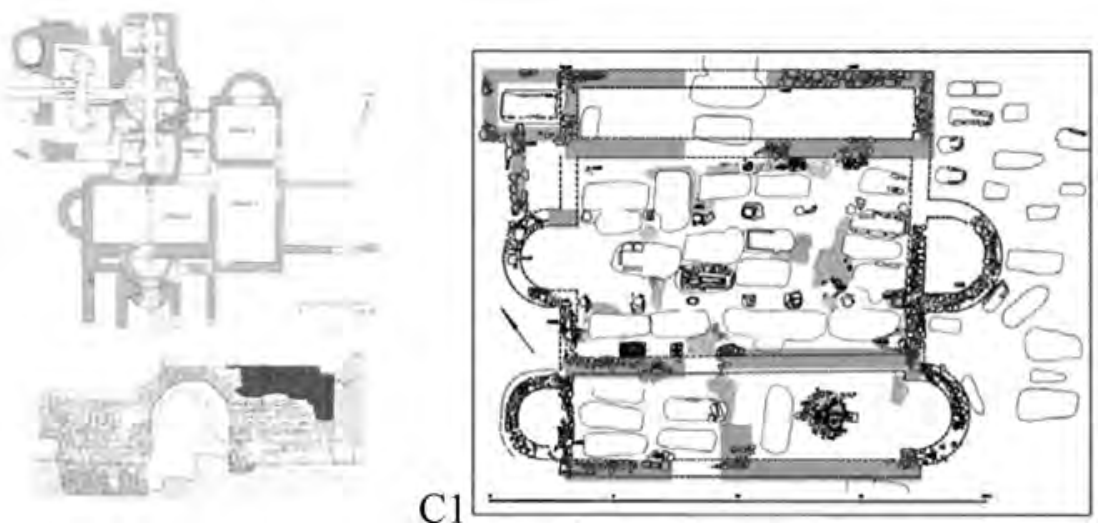

El edificio bautismal de El Germo (C3) es el único que, con total seguridad, puede calificarse como tal. Se trata de un cuerpo adosado a la basílica por su lado sur, que reproduce la estructura de doble ábside de ésta, creando una original arquitectura, simétrica a la crujía norte del mismo edificio, que se une también a la basílica, pero sin ábsides en esta ocasión. Pensamos que dicho edificio estaría dividido en dos salas, separadas por una acceso hacia la basílica, y que dividiría claramente el espacio del bautismo (con su piscina) al sureste, de un espacio casi repleto de tumbas, al suroeste. No sabemos si los ábsides tenían una función litúrgica, es decir, llegaron a poseer altares, como en el caso de Casa Herrera (Sastre de Diego 2010). Arquitectónicamente hablando, el ábside más alejado de la piscina bautismal cuenta con un muro que, quizás, pudiera indicar la elevación necesaria para sustentar el altar como espacio privilegiado. Aunque esto no es seguro y es posible que estemos ante un recurso arquitectónico para salvar al desnivel del terreno. No podemos estar seguros. En el caso antes mencionado de Casa Herrera el altar está junto a la piscina, algo lógico si pensamos que, tras el bautismo, se produce la primera comunión de los competentes. Sin embargo, a favor de que el altar se encuentre en esta zona estaría la presencia de las tumbas.

La ubicación del edificio bautismal junto al altar, en un edificio anexo y compartimentado, tiene sus principales analogías en las iglesias baleares (Fig. 2) de Cap des Port y Torelló (Alcaide 2011) que cuentan este tipo de instalaciones, pero situadas en su fachada norte. En cambio, Son Fadrinet (Alcaide 2011) cuenta con un complejo edificio anexo al sur de la iglesia, pero situado a sus pies. Mucho más complejo, y prácticamente un edificio independiente, sería el edificio bautismal de Torre de Palma (Schlunk; Hauschild 1978: 172-174). En la villa de la Dehesa de la Cocosa, un pequeño edificio bautismal se sitúa al sur del edificio 
tetraconque, y también se divide en dos salas (Godoy 1995: 274-276), de forma muy similar a lo que ocurre en Casa Herrera. Hasta ahora, en la Península, no existen más ejemplos que este cordobés para ubicar piscinas bautismales en edificios absidados, o doblemente absidados.

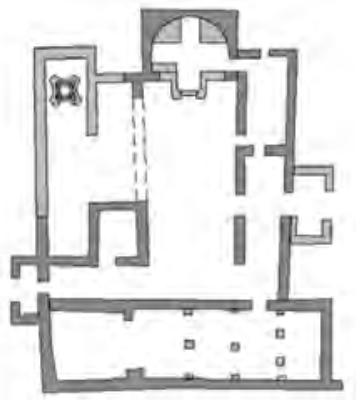

a

Figura 2 - Ubicación de los edificios bautismales en las iglesias baleáricas (a partir de Alcaide 2011): a) Cap des Port; b) Torelló; c) Son Fadrinet.

De confirmarse que el edificio L de Cercadilla (C4) fuera un edificio bautismal, se situaría al sur de la basílica principal del complejo, y con varios ambientes absidados, aunque su singularidad a nivel de planta y ubicación se derivaría directamente de la asignación a un momento muy inicial de la arquitectura cristiana, casi de experimentación (Krautheimer 1996). Esta misma articulación de basílica-zona de tránsito-baptisterio en tres unidades edificadas bien diferenciadas (y edificadas conjuntamente o no), la encontramos en numerosas ocasiones a lo largo del Mediterráneo en la época que nos ocupa: el patriarchio Lateranense (De Blaauw 2004: 11-12; Liverani 2004, fig. 13; ya en el s. iv); la basílica meridional de Tarraco (López Vilar 2006, s. v); la basílica episcopal de Valentia (Ribera i Lacomba 2008, s. vi); Casa Herrera (Sastre de Diego 2009, s. vi); etc.

\subsubsection{Salas anexas}

B1

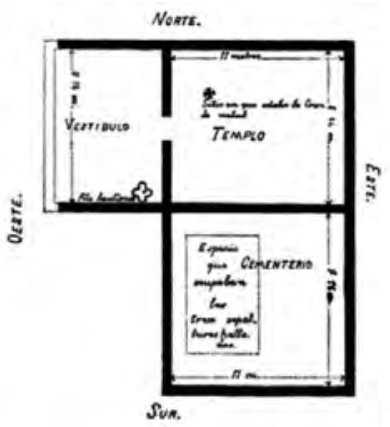

S1

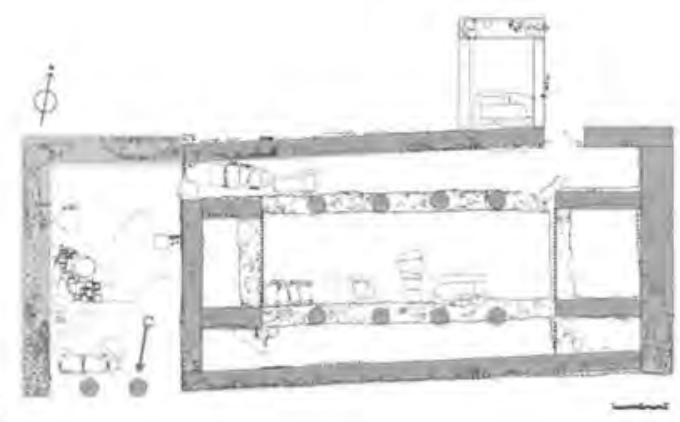


Igualmente singulares serían lo que hemos denominado salas anexas. Las hemos denominado así porque se encuentran abiertas, sin clausurar, algo para lo que no hemos encontrado paralelos. Su ubicación a los pies de los templos sí tiene multitud de paralelos. Gran parte de los baptisterios hispanos se ubican así respecto a sus iglesias (Schlunk; Hauschild 1978: 51). Atendiendo a los datos que poseemos para Egara, esta ubicación sería más moderna que la que sitúa los baptisterios junto a las cabeceras de las iglesias (García; Moro; Tuset 2009: 80-106). De hecho, en el espacio de aproximadamente unos 50 años, entre la fase preepiscopal III (380) y la IV (420-430 d.C.), el baptisterio cambia radicalmente de localización, desde la cabecera de iglesia episcopal a los pies de la misma. No sabemos si este cambio se produjo por cuestiones litúrgicas o debido a problemas estructurales. Sin embargo, todos se encuentran dentro de edificios y/o estancias cerradas. Tan sólo en el caso de Son Peretó (Fig. 3), ocurre algo similar a estos baptisterios béticos, con un acceso extraordinariamente generoso a esta instalación litúrgica.

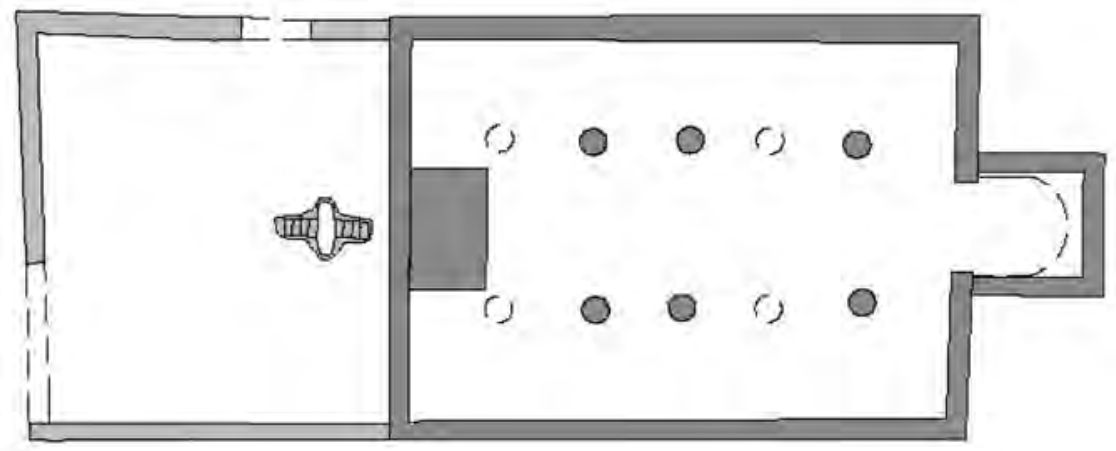

Figura 3 - Planta de la basílica de Son Peretó (a partir de Alcaide 2011).

Con los datos actuales no sabemos si estas estancias estarían cerradas por canceles metálicos o alguna otra estructura. Habría que confirmar, a través de excavación, que se tratan de unidades habitacionales abiertas, tal y como las hemos detectado, asimismo, en monumentos funerarios, que se encuentra abiertos, sin muros de cierre, y en los que (gracias al mausoleo de Punta del Moral) hemos podido saber que - muy probablemente- se clausuraban tapiando con adobes enlucidos los accesos. No sabemos si esto ocurrió así en los baptisterios, o permanecieron abiertos. Pero es una posibilidad a tener en cuenta. En este sentido, hay que recordar que la simbología bautismal tenía fuertes concomitancias con la propiamente funeraria. Así, Ambrosio de Milán (Ferguson 2009: 643-644) explicaba el ritual del bautismo de forma frecuente en términos de muerte, entierro (demergimur) y resurrección (surgimus), equiparando el rito con la crucifixión y con una muerte al pecado. Inclu- 
so va más allá, porque para él "Hesterno die de fonte disputavimus, cuius species ueluti quaedam sepulchri forma est" (Sacr. 3.1.1). Por tanto, el propio baptisterio era, en su interpretación teológica, una tumba.

¿Sería, pues, posible, que estos baptisterios se encontraran clausurados, literalmente tapiados, y sólo se abrieran en la fecha señalada para su uso, imitando los recintos funerarios? La hipótesis de trabajo queda planteada ante la evidente falta de cierre de estas estancias, confirmada con seguridad en Gerena y de forma probable en Burguillos del Cerro. En el caso de Gerena, incluso, contaríamos con un edificio funerario privilegiado, junto a la cabecera, que quedaría abierto, según la hipótesis que planteamos de restitución en base a los restos materiales, conformando el paralelo "más cercano" de esta situación, dentro de un mismo edificio; sería similar al caso de Valentia (vid. infra). A todo ello que habría que añadir que, en el caso de El Germo (C3), único edificio bautismal determinado con seguridad, su tipología es muy similar a los grandes mausoleos de planta basilical de Coracho (C17) o La Trinidad (S7), y su parte occidental, de hecho, sirve de sala de enterramientos. En este sentido, las tipologías de edificios bautismales en otros lugares de Hispania o del Mediterráneo se asemejan, igualmente, a edificios funerarios, predominando en este caso la planta central o cruciforme (Ristow 1998; Ferguson 2009). El caso más destacado en la Península sería, sin duda, la catedral de Valentia, donde dos edificios cruciformes a cada lado del ábside principal sirven de mausoleo y de baptisterio, respectivamente.

Sin embargo, sin más datos de más excavaciones con un mayor índice de seguridad respecto a la clausura o apertura de estos edificios, así como de los funerarios, este tipo de propuestas deben quedar en el estricto ámbito de la hipótesis.

\subsection{Baptisterios}

Por baptisterios entiéndase piscina bautismales stricto sensu. Seguimos aquí, en parte, las tipologías sobre piscinas bautismales existentes para Hispania (Fig. 4 a partir de Schlunk; Hauschild 1978: 51, fig. 27) y para el Imperio (Ristow 1998: 27-52), aunque con ligeras variantes, básicamente para aquellos que cuentan con piscinas anexas.

Sin embargo, una cuestión mucho más complicada es la cronológica, ya que, salvo casos muy concretos, resulta casi imposible adscribir un tipo de forma de la piscina un momento concreto, sobre todo porque en los repertorios existentes (vid. Ristow 53-76) se asumen cronologías dudosas. Pensamos que, en el momento actual, habría que realizar una profunda revisión de este tipo de instalaciones, especialmente en Hispania (donde haría falta sin duda publicaciones monográficas como las existentes en Italia o Francia), tratando de centrar el debate cronológico más en datos de excavación rigurosos que en la posible comparación con la forma, la profundidad de las piscinas y sus aspectos litúrgicos, como se ha hecho hasta ahora (Godoy 1989). Sólo cuando tengamos datos 
fiables y seguros sobre la cronología de las piscinas se podrán aplicar criterios tipológicos a aquellas que no es posible datar a través del registro arqueológico (y siempre con reservas y señalando otro tipo de argumentos).

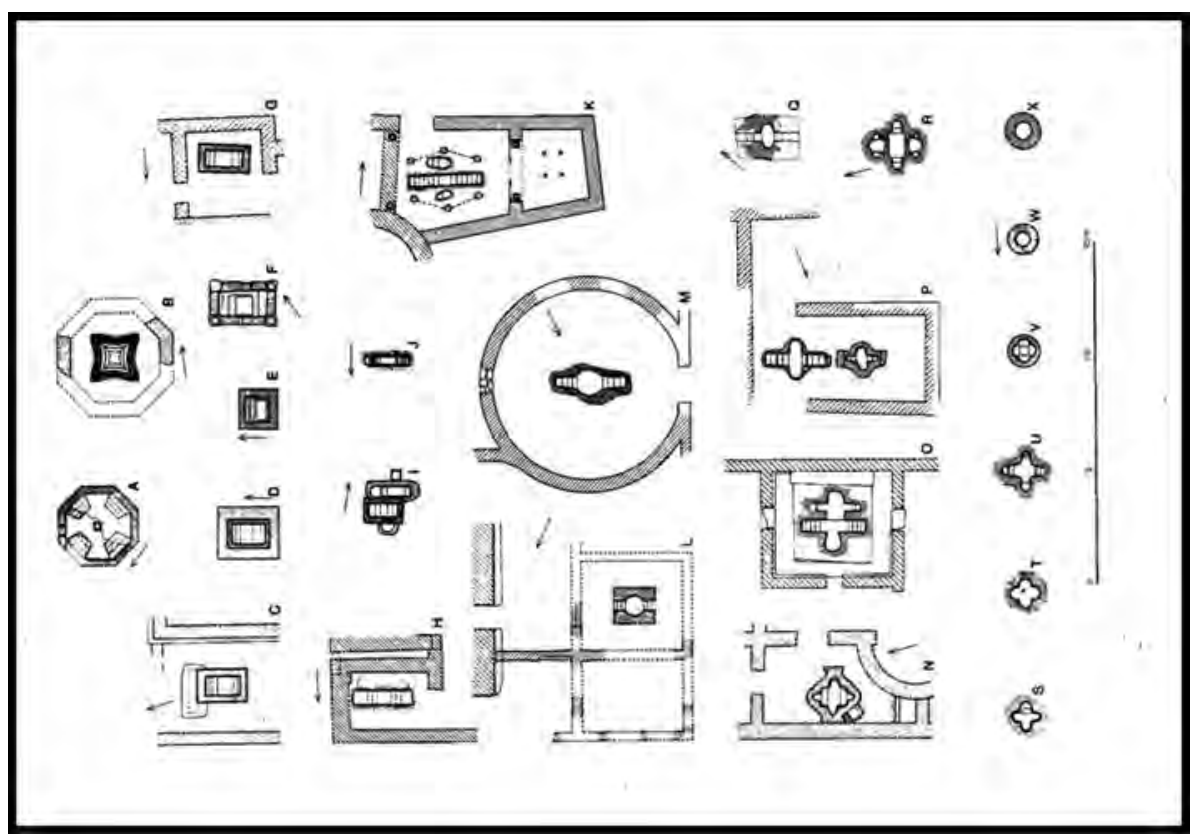

Figura 4 - Baptisterios de Hispania (Schlunk; Hauschild 1978, fig. 27.

Y si complicada es la cronología, la simbología no lo es menos, porque es posible que la forma elegida para el tipo de piscinas (muy heterogéneo como ya hemos mencionado) esté en función de que se pretende incidir en alguno de los múltiples aspectos teológico-simbólicos que envuelven el rito del bautismo. Al igual que con los edificios bautismales, ya analizados (vid. supra), es posible que la elección de un tipo de forma u otro resida en si se pretende resaltar o la imitación del bautismo de Cristo (con una fons) o la simbología de la muerte al pecado (con una cruz). El primer baptisterio del que tenemos evidencia arqueológica es el de Doura Europos (Ferguson 2009: 440-441), fechado a mediados del siglo in d.C. (la ciudad es arrasada por los sasánidas en 256 d.C.) y que estructuralmente parece un arcosolio o alguna de las estructuras conmemorativas que el Papa Dámaso (366-384 d.C.) coloca en honor de los Santos Pedro y Marcelino en la catacumba homónima en Via Labicana o de San Genaro en la de Pretestato (Via Appia) (Fiocchi Nicolai, 2001: 80-81, Figs. 52-53). Sin embargo, los grandes baptisterios monumentales del siglo iv d.C. tienen una importante carga simbólica de reproducción teatral del bautismo de Cristo, como el baptisterio lateranense (Cosentino 2001) provisto de importantes sistemas hidráulicos que permitían el 
concurso de grandes cantidades de agua, una columna central sobre la que existía una llama que simbolizaba el descenso del Espíritu Santo y varias esculturas de animales, que recreaban un paisaje idealizado, de Naturaleza, de lo que se pensaba podía ser la orilla del Jordán.

No sabemos en qué grado las teorías ambrosianas sobre bautismo y muerte estaban presentes en Hispania, y hasta qué punto pudieron influir en la construcción de baptisterios o piscinas bautismales. Lo que sí parece seguro es que, mientras en Italia (Gandolfi 2001) y Gallia (Guyon 2000; I. 2006) se fomenta la fons circular u octogonal y la recreación peripatética del bautismo de Cristo, en la Bética apenas se da esta tipología, excepto en el caso del baptisterio de La Merced (C5).

\subsubsection{Cuadrangulares - Quadratish Form de Ristow 1998}

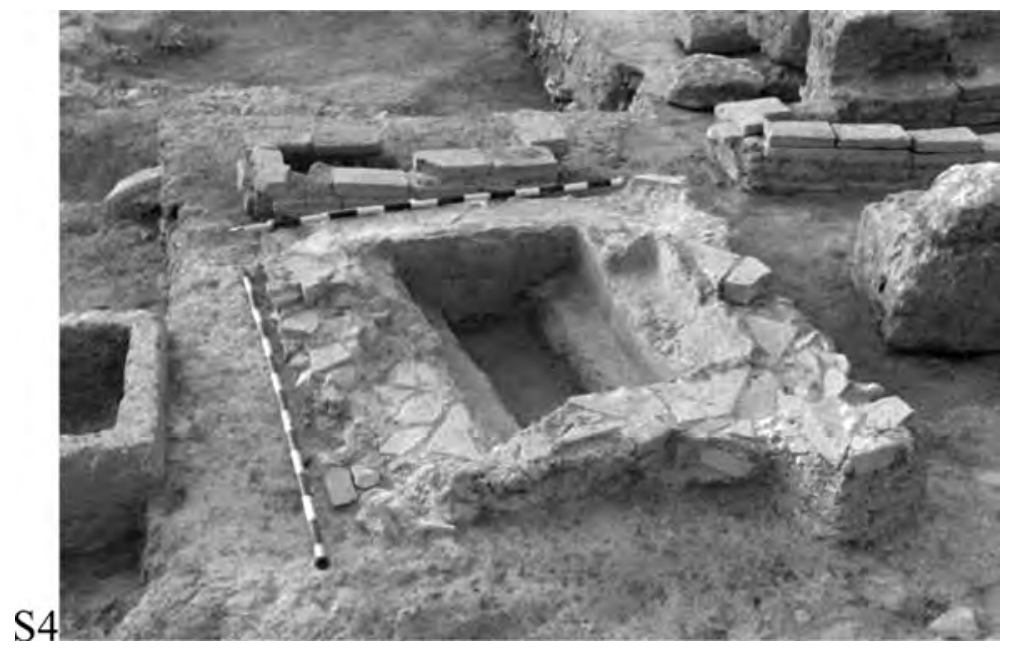

Para Schlunk y Hauschild (1978) este tipo se incluiría dentro de las piscinas con "Rechteckige Form", de las que no las distinguen. El único ejemplar conocido en la Bética Occ. sería el de Estepa, de problemática datación. Este tipo de instalaciones supondrían, según la encuesta de Ristow (1998: 28, grf. 5) un 9\% del total de baptisterios. Si nos centramos en Hispania, los ejemplos son numerosos: Milreu, Tarragona, Bobalá, Villa Fortunatus o la Cocosa. Poco más se puede decir de este tipo en el caso de la Bética Occ., a la espera de que sea publicadas las memorias de excavación y revisión de las antiguas intervenciones. 
VETERA CHRISTIANA MONUMENTA IN BAETICA. Hacia una sistematización de la arquitectura de época tardoantigua en la parte occidental de la provincia

\subsubsection{Con forma de Tau. Rectangulares con piscina auxiliar anexa.}
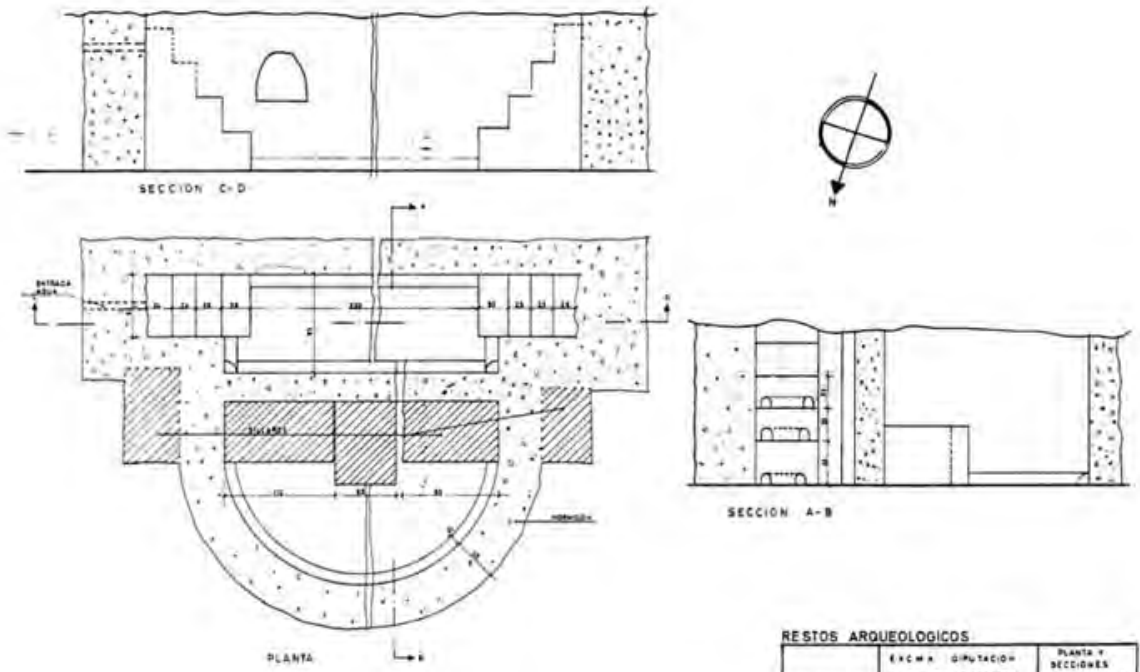

En la Península encontramos varios ejemplos de esta tipología, que generalmente se ha descrito como perteneciente al tipo Rechteckige (si las piscinas estaban separadas) o al Kreuzform (si estaban junta y/o unidas al cuerpo principal). Córdoba contaría con un ejemplo de esta tipología, al menos hasta que se resuelva definitivamente (a través de una intervención arqueológica en lo poco que queda de la estructura) si se trata de una unidad o son dos momentos diferentes los que aparecen en esta instalación: por un lado el cuerpo rectangular y, por otro, el semicircular. Ya hemos expresado, en su momento (Sánchez Velasco 2006), las causas que nos llevan a considerar estos restos como un baptisterio, y además uno de los más antiguos de la Península, debido a su complicado sistema hidráulico, propio de los inicios del rito bautismal, donde la necesidad de agua corriente era un requisito, futo de la propia recreación del primer bautismo, el de Cristo. En este sentido, la existencia de esta piscina anexa semicircular estaría en función del oficiante (el obispo) y su asistente (un diácono), mientras que el cuerpo rectangular, orientado E-O como es preceptivo, serviría para que los competentes hicieran el recorrido ritual de entrada-salida, con toda la simbología de muerte al pecado y resurrección a una nueva vida. Esta explicación, ya publicada hace tiempo (Godoy 1989: 622-623), parece ser la más convincente. Hasta el momento, tan sólo uno de los baptisterios de Idanha-a-Velha parecía corresponderse con una tipología similar, aunque la existencia, a su lado, de otro cruciforme más pequeño hacía mantener ciertas dudas, especialmente debido a la monumentalidad del cordobés. Sin embargo, el hallazgo reciente del baptisterio de Vila Verde de Ficalho 
(Serpa, en Portugal, en el límite entre Lusitania y Bética) ${ }^{8}$, parece confirmar la presencia de esta tipología específica (Fig. 5).
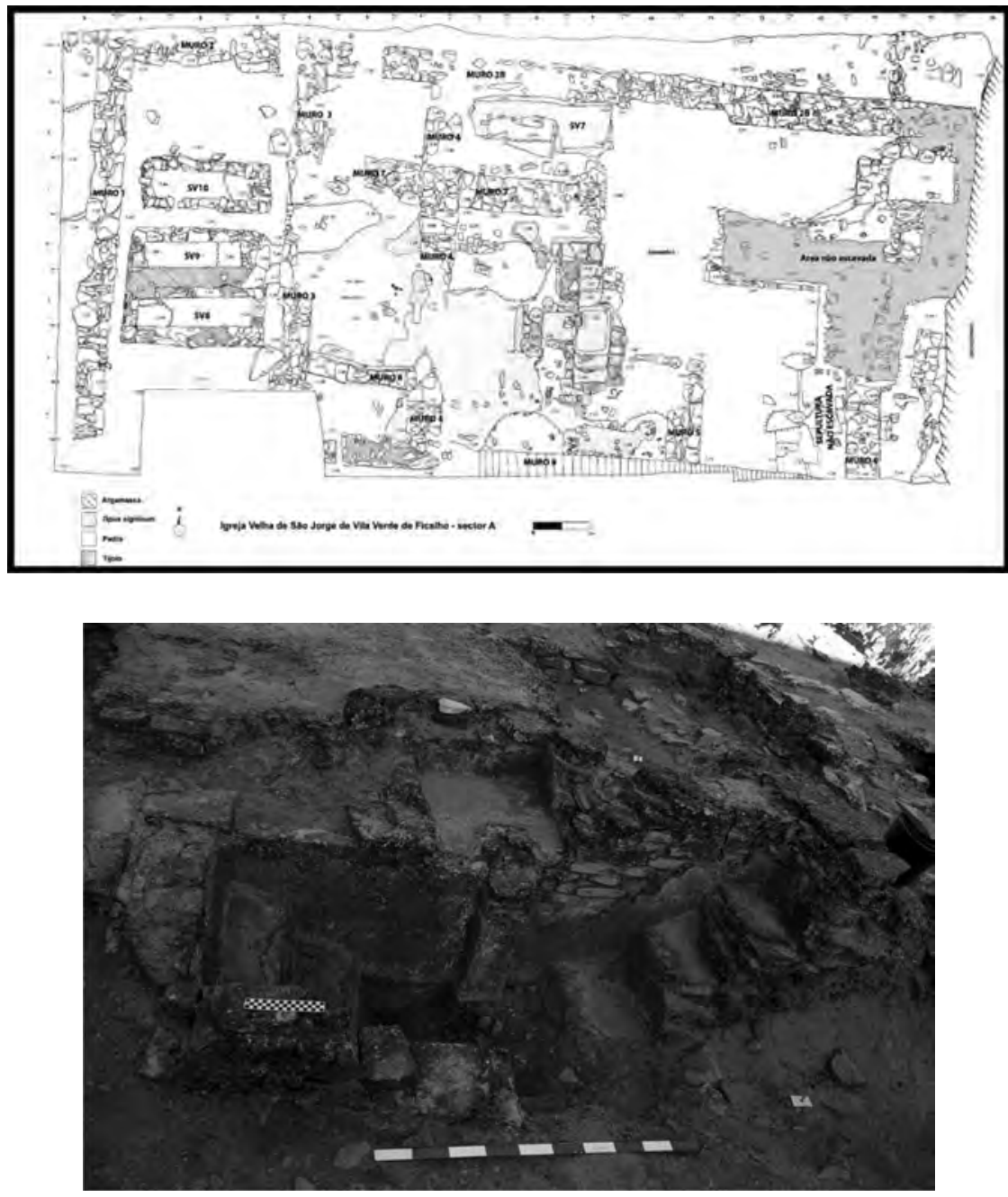

Figura 5 - Planta de la excavación (arriba) y fotografía de detalle (abajo) del baptisterio de Ficalho (Wolfram 2012).

${ }^{8}$ Queremos agradecer encarecidamente a la responsable del proyecto de investigación que está revisando esta excavación, Mélanie Wolfram, que nos haya facilitado los datos inéditos de su investigación, así como variada documentación gráfica. En agosto de 2010 pudo reexcavar la zona, con pocos resultados, aunque el estudio de la TS de la excavación de los años '90 del siglo xx (de la que no se conserva memoria final de la misma), confrontados con los suyos propios, parecen indicar una datación entre finales del s. Iv e inicios del v d.C. 
VETERA CHRISTIANA MONUMENTA IN BAETICA. Hacia una sistematización de la arquitectura de época tardoantigua en la parte occidental de la provincia

\subsubsection{Cruciformes - Kreuzform de Schlunk-Hauschild 1978, Ristow 1998}

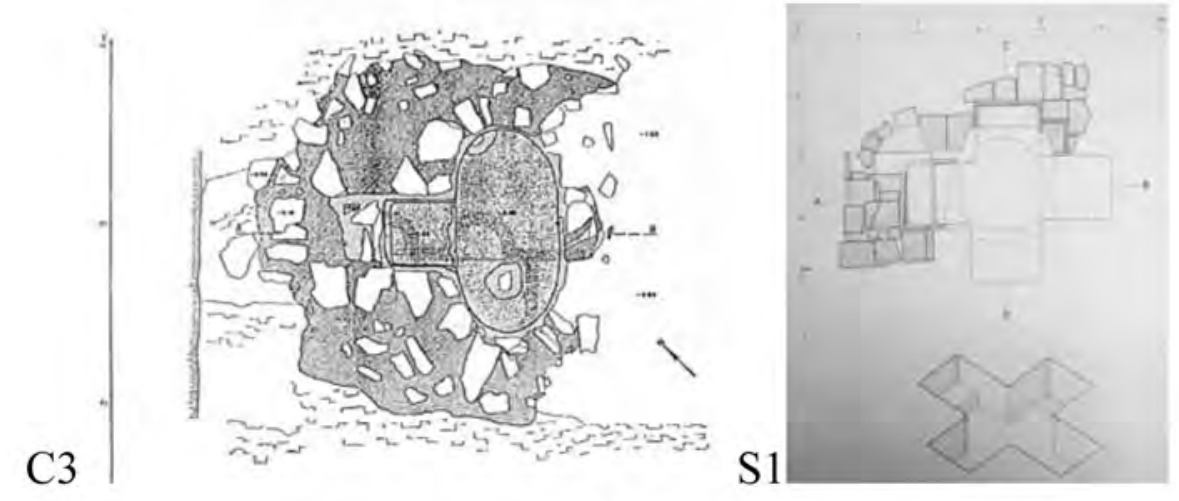

B1
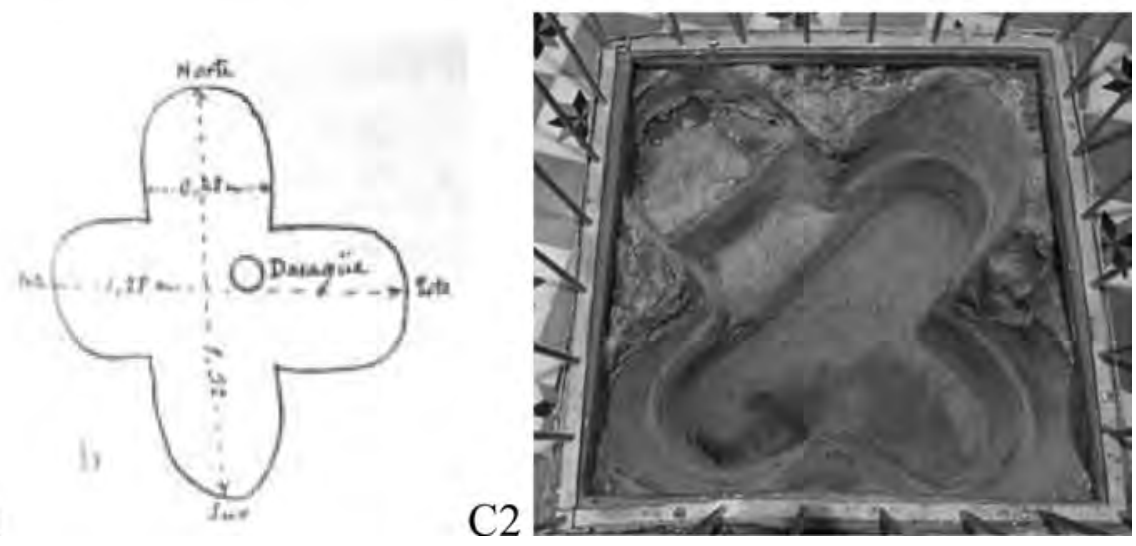

Está considerada la forma "típica" de los baptisterios béticos, siendo casi un 16\% en la estadística aportada por Ristow (1998: 28, grf. 5). Desde luego, y ateniéndonos al territorio que estudiamos, es la forma hegemónica sin duda, con los ejemplos de E1 Guijo (C2), E1 Germo (C3), Burguillos del Cerro (B1) y Gerena (S1), aunque tan sólo el primero y el tercero responderían a una misma forma. Es complicado hablar de cronologías, aunque con los datos conocidos de El Germo (C3) y Gerena (S1) se podría proponer una datación aproximada entre inicios del siglo vi e inicios del viI d.C., con muchas reservas.

$\mathrm{Su}$ forma habría que relacionarla, tal vez, con la simbología expresada en los escritos teológicos sobre el bautismo que ya hemos visto en Ambrosio de Milán (Ferguson 2009: 642 ss) donde el baptisterio tenía forma de tumba y la ceremonia era un símbolo de la crucifixión. 
3.4.4. Cubetas - Kleine runde Taufbecken (Scblunk; Hauschild 1978) y Rund Form (Ristow 1998)

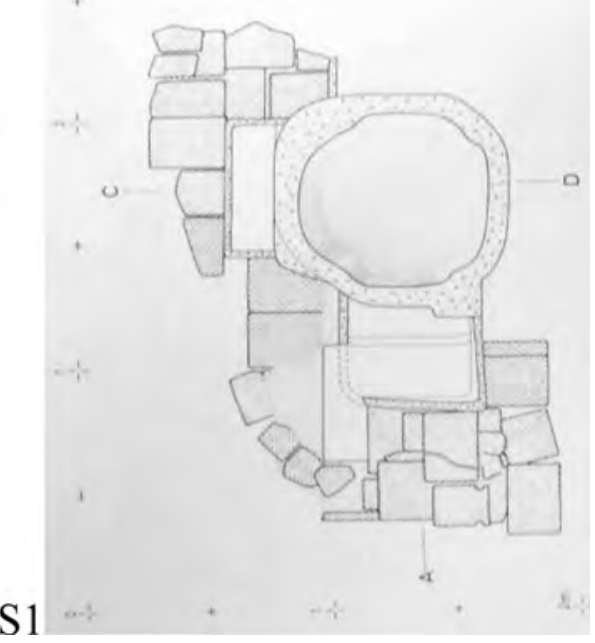

Es, con mucha diferencia (un 30\% del total estudiado por Ristow), el tipo de instalación bautismal más común en la koiné mediterránea. Estas cubetas se caracterizan por ser redondas, de pequeño radio y de escasa profundidad, construyéndose en obra o tallándose en un bloque monolítico, como el que nos ocupa, y que tiene un paralelo en la hallada en Son Bou (aunque esta se encuentre decorada al interior con cuatro lóbulos).

En el estudio que hemos realizado de Gerena (vid. S1) ya hemos señalado algunos paralelos destacados de esta estructura, que tiene un amplio recorrido temporal, aunque para el caso concreto que nos ocupa pensemos que habría que aplicar una cronología bastante tardía, de la segunda mitad del vir d.C. al menos, atendiendo a cierta lógica de amortización de las estructuras preexistentes.

\subsection{Complejos monásticos}

Conocemos la existencia de monjes en Hispania desde, al menos, el siglo Iv d.C., y de una forma similar a su entorno mediterráneo (Marcos 2006), aunque sólo a través de los textos, de las polémicas priscilianistas y de los concilios de ese siglo (Elvira, Zaragoza), aunque su "realidad material" es un problema. Nos parece muy acertada (al menos para la Bética occidental) parte de la conclusión a la que llega Moreno Martín (2009: 300) cuando afirma que, antes de la unificación y normalización benedictina del monasterio románico, las diferentes soluciones arquitectónicas para crear un monasterio debieron estar llenas de particularismos y localismos, fruto de un proceso expansivo no definido que se amoldará a las 
necesidades de cada momento y territorio. Igualmente, coincidimos con este investigador en que se ha dado poca importancia a los monasterios urbanos y periurbanos, algo que, si nos atenemos a la nómina de los mismos obtenida a partir de los textos (Puertas Tricas 1978), carece de lógica. Tal vez, la propia indefinición material de estos monasterios, así como la falta de referentes arquitectónicos unívocos (nada nuevo en la arquitectura tardía bética), haya hecho pensar en los monasterios como establecimientos rurales ubicados en lugares inhóspitos y apartados.

\subsubsection{Monasterios Urbanos}

Tan sólo tenemos documentadas arqueológicamente unas estructuras capaces de relacionarse con ambientes monásticos: el llamado edificio K de Cercadilla. Su estructura,tamaño yubicación esidéntica a los diferentes monasterios que rodearon San Pedro del Vaticano (De Blaauw 2010) o San Juan de Letrán (Liverani 2004), y que sufrieron constantes añadidos, hasta el punto de que, en el siglo viII-IX, formaban auténticas ciudades dentro de Roma (Ciuitas Leoniana llamaron al entorno de San Pedro del Vaticano tras el amurallamiento de la zona por el Papa León IV en 852 d.C.: vid. Brenk 2005: 141-143). Sin embargo, este es un extremo que, como prácticamente todo lo relacionado con Cercadilla, necesitaría de nuevas investigaciones multidisciplinares para conseguir datos arqueológicos fiables. Aunque, en nuestra opinión, la existencia en Córdoba de esa nómina tan abultada de monasterios en época omeya debe tener parte de su explicación en época visigoda.

Nuestra hipótesis sobre la definición como monasterio periurbano de los restos hallados en el Patio de Banderas (Ordóñez et al. 2013) debe esperar a mayores excavaciones para ser confirmada, más allá de la mera especulación científica a nivel interpretativo.

\subsubsection{Monasterios Rurales}

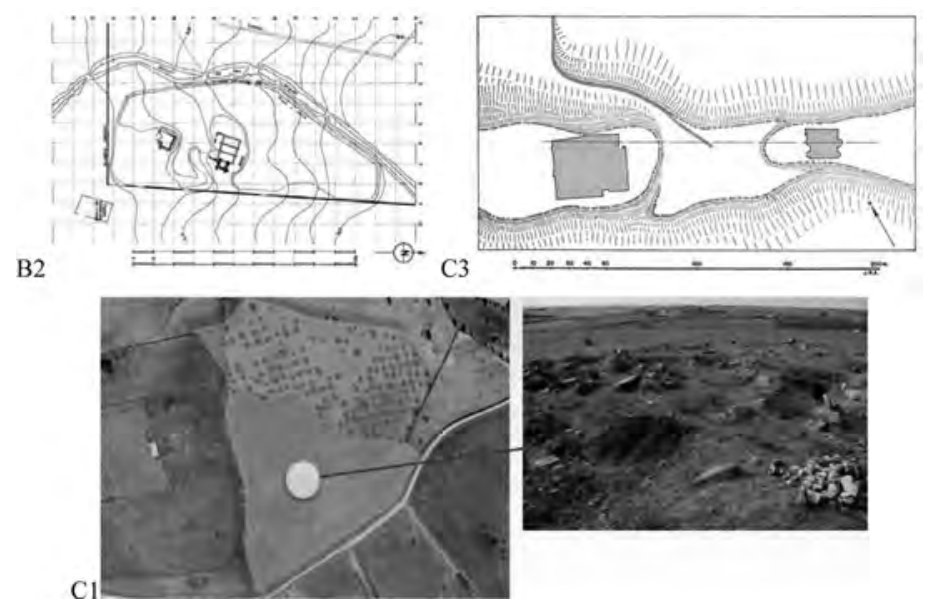


Tres son los emplazamientos que, pensamos, se corresponderían con monasterios rurales: E1 Germo (C3), La Losilla (C1) y San Miguel de los Fresnos (B2). Sin embargo, el desconocimiento de su realidad arqueológica (más allá del propio templo, se entiende) invita a ser prudentes, porque en realidad la definición de un monasterio se hace gracias, fundamentalmente, a las dependencias funcionales, no a las religiosas, ya que no existe un "tipo" de iglesia monacal (Moreno Martín 2009: 282). De hecho, hasta la regula de Isidoro de Sevilla, no tenemos una clara definición de qué es un monasterio, aunque lo que se plantea en su primer cánon es más bien un desideratum que una realidad material que sirva de posible referente arqueológico: es un modelo, como Sant Gall, donde la realidad es totalmente diferente al supuesto prototipo (Moreno Martín 2009: 280). Y esto es así para el siglo viı d.C.; para épocas anteriores la oscuridad documental es casi total. Por consiguiente, la definición del monasterio deberá ser, de forma necesaria, un hecho básicamente arqueológico, y en la Bética especialmente, donde la nómina de estos establecimientos es ingente a nivel textual (Puertas Tricas 1975) y casi nula a nivel material.

A pesar de todo lo dicho, hay que mencionar que estos establecimientos comparten ciertas características comunes: grandes iglesias, extremadamente grandes - si las comparamos con las halladas estrictamente en ámbitos rurales - y complejas arquitectónicamente (doble ábside, sistema de abovedamiento de la nave central...) en relación a los restos constructivos de edificios funcionales ubicados junto a ellas; importante acumulación de enterramientos en el interior de las iglesias; edificios alejados de los templos que tienen características de arquitectura doméstica, aunque no se correspondan con domus o uillae conocidas; organización en terrazas de las diferentes construcciones; espacio general delimitado, ya sea por cercas o por la propia orografía; más que posible existencia de unidades de habitación realizadas en soportes deleznables, como chozas o casas de madera, aunque esto último debe ser documentado arqueológicamente; ubicación en lugares alejados, pero bien comunicados, ocupando importantes áreas agrícolas o ganaderas, magníficamente abastecidas de agua.

El único caso totalmente excavado y (muy bien) publicado en varias ocasiones es E1 Germo (vid. C3). Aunque se planteó en un primer momento que fuera un monasterio, Ulbert (1981) lo desestima, considerando el lugar como un edificio laico ("profanbau", aunque no dice que sea una villa, ni tampoco lo define), extremo en el que es seguido por Godoy (1995:272) y por Caballero (2006: 111). Martínez Tejera (2007: 34) también lo descarta - colateralmente - aduciendo que la clave para la definición del monasterio frente a una parroquia rural es la unión física entre iglesia y edificios funcionales. Moreno Martín (2009: 283) sólo cita que la inclusión de El Germo como monasterio es la "hipótesis que ha sido aceptada".

Nosotros nos inclinamos por definir El Germo como un monasterio (vid. C3), tanto por su características arquitectónicas como por las funcionales, topográficas y territoriales, además de por los hallazgos muebles encontrados y la 
epigrafía descubierta. En nuestra opinión, comparte características con otros yacimientos que, con pocas dudas, se ubican en la nómina de monasterios hispanos, como Punta de l'Illa, en Cullera (Roselló 2005: 282-285; Ribera-Roselló 2007: 163-164), con estructuras dispersas a lo largo de toda la isla: la zona I considerada la iglesia; la zona II, cellaria; la zona III, celdas múltiples y dispersas. Esta misma dispersión, pero a una escala mucho mayor, se encuentra en el área septentrional del complejo paleocristiano del Francolì, considerado - con muchas posibilidades - como un monasterio extraurbano (López 2006: 270-275) y sin muro de cierre aparente. Otros lugares, considerados - sin ninguna objeción y de forma muy probable - como monasterios rurales en atención a su templo y a sus arquitecturas anexas, apenas cuenta con posibilidades reales de atisbar la funcionalidad de estas estructuras (Moreno Martín 2009: 286; Caballero 2007: 95-96). A pesar de que la realidad material es escasa, tanto por el emplazamiento como por su necrópolis, habría que considerar los restos hallados en El Arahal (S5) como un posible conjunto monacal, al menos como hipótesis de trabajo explicativa de un edificio y una necrópolis de importancia en pleno ámbito rural.

Por consiguiente, habrá que esperar a que más excavaciones o nuevos hallazgos nos ayuden a configurar mejor estas realidades arquitectónicas, que hasta ahora se resisten a ser definidas con corrección en la Bética Occidental.

\subsection{3. ¿Cenobios rupestres?}

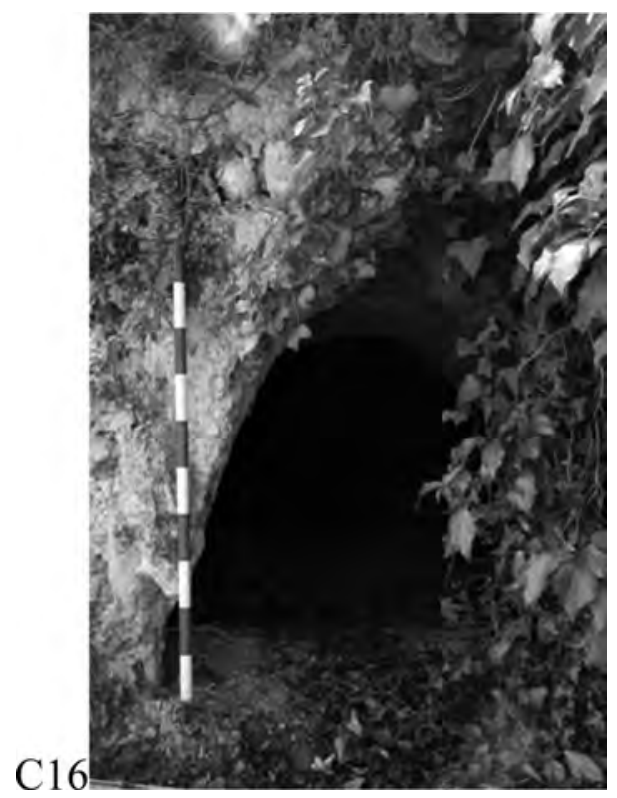

Bien se cierto que no todas las oquedades artificiales son eremitorios (Martín Viso 1999: 163), pero pensamos que en este caso (El Arrimadizo) las pruebas 
aducidas son bastante sólidas, especialmente teniendo en cuenta la necrópolis y la inscripción hallada (vid. C16).

Siguiendo a Martínez Tejera (2007: 20) en su definición de los tres tipos de espacios "monásticos" presentes, según los textos de la época, en la Hispania tardoantigua, pensamos que las tres covachas halladas en El Arrimadizo podrían corresponderse con lauras para eremitas. Desde luego, esto es sólo una hipótesis en espera de una mayor documentación arqueológica del lugar (muy arrasado, por cierto), pero en este caso habría de existir alguna zona de, digámoslo así, "hábitat común". En este caso, la única zona de estas características sería el cementerio hallado justo sobre estas lauras. La profusa vegetación, la abundancia de agua (con cascadas y numerosos arroyos) y el paisaje circundante nos hace pensar en las descripciones que hace Eucherius del monasterio de Honoratus en Lérins (fundado a inicios del s. v d.C.), y recogidas en De laude eremi, donde prácticamente define el monasterio como un paraíso terrenal de sentidos y Naturaleza.

En la cercana Cabra contamos con documentos epigráficos que mencionan expresamente a un monachus (CIL II ${ }^{2} / 7,333$ ), eso sí, en si siglo viI d.C. Y ya publicamos (Sánchez; Moreno; Gómez 2009) la posible incidencia de estas comunidades en la zona a la hora de comprender ciertas destrucciones relacionadas con centros de culto pagano rurales, como el caso aducido de Almedinilla (Sánchez-Moreno-Gómez 2009: 175-176). Este tipo de comportamientos intransigentes los conocemos bien gracias a los relatos sobre Martín de Tours y sus ataques a templos paganos, urbanos y rurales (Marcos 2001). La cruz en forma de ankh hallada en Priego de Córdoba (Sánchez-Moreno-Gómez 2009: 173-175), y fechada en el siglo iv d.C., tal vez esté en relación con este tipo de comunidades, aunque no podemos saberlo.

Por consiguiente, pensamos que estas oquedades podrían ser una prueba más de monjes y eremitas en esta zona, tan tempranamente cristianizada de la Bética Occidental.

\section{Torres}

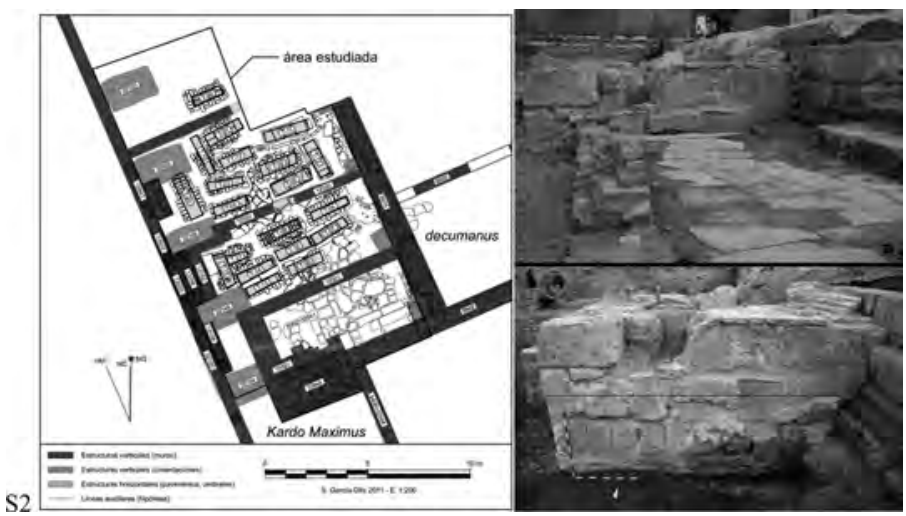


La presencia de una torre no se debe relacionar, sin crítica, con la existencia de campanas, así como las campanas no exigían necesariamente la presencia de torres, ni altas ni bajas. Sabemos de la existencia de campanas sin torres y de torres sin campanas. De este modo, no se habla de campanas en el testimonio literario hispano más antiguo relativo a las torres de una iglesia: las Vitas sanctorum patrum emeritensium, del s. viI, aseguran que el obispo Fidel (560-571) "restauró" allí la memoria de Santa Eulalia y "sobre este sacrosanto templo elevó las puntas empinadas de las torres a sublime altura" (Arbeiter 2010: 27). Las excavaciones han confirmado con bastante seguridad la situación de las citadas torres, porque aún existen restos de las partes inferiores, formando pareja en la cabecera de la iglesia y, a su vez, en el interior de la planta baja tenían sendas habitaciones con ábsides. En las V.S.P.E. no se dice nada de campanas, y las torres tal vez estén relacionadas con el carácter martirial de la iglesia, consagrada a la mártir más famosa de Hispania.

También dos iglesias monásticas rurales, que se han datado en el s. viI, cuentan con torres aunque en ambos casos una torre única y además independiente del templo (Arbeiter 2010: 28): São Gião, al sur de Nazaré (Leiria, Portugal), en cuyo flanco derecho perduran las huellas de una estructura cuadrangular, y Santa Lucía del Trampal, cerca de Alcuéscar (Cáceres), donde en la esquina noroccidental se hallan restos de muros, a partir de los cuales se ha reconstruido una torre cuadrangular. Al igual que en la iglesia emeritense de Santa Eulalia, no se sabe nada sobre posibles campanas. También se ha supuesto la existencia de torres en San Vicente de Córdoba y en la catedral de Toledo, a partir de ciertos testimonios de escritores árabes (Arbeiter 2010:29-30). Igualmente ocurre para la iglesia que se menciona en las crónicas árabes que tratan el asalto vikingo a Sevilla, donde se menciona que se divisó la flota asaltante desde la torre de dicho templo, cercano a Orippo (García-Sánchez 2010).

Como vemos, y al menos en el ambiente hispano, la relación entre torre e iglesia parece ser estrecha, aunque no necesariamente implique la existencia de un campanario, y su función precisa se nos escapa, al menos en el único caso que conocemos con total seguridad a nivel arqueológico (éste de Écija), y hasta que no se revisen por completo todos los materiales procedentes de las sucesivas excavaciones del lugar (labor que estamos realizando) no será aconsejable emitir una hipótesis de trabajo.

\section{Propileos}

Ya hemos resaltado en su momento los numerosos ejemplos de este tipo de construcciones a lo largo de todo el arco mediterráneo, y especialmente en Hispania, con motivo del análisis del complejo arquitectónico de la c/ Mármoles (vid. S8). Por ello no nos detendremos más en esta cuestión, aunque nos gustaría hacer notar una apreciación más general: allí donde se han documentado estas 
estructuras en Hispania se baraja la existencia de un complejo episcopal (Valentia, y - posiblemente - Tarraco o Corduba), mientras en otras zonas del Mediterráneo, como Italia (San Lorenzo de Milán) o Palestina (la Anástasis de Jerusalén), estas estructuras se asocian a ambientes martiriales y/o conmemorativos, relacionados con el culto estacional. Esto no significa, automáticamente, que la aparición de estos propileos suponga la existencia de un episcopium, sólo que existe esa posibilidad, al menos en Hispania.

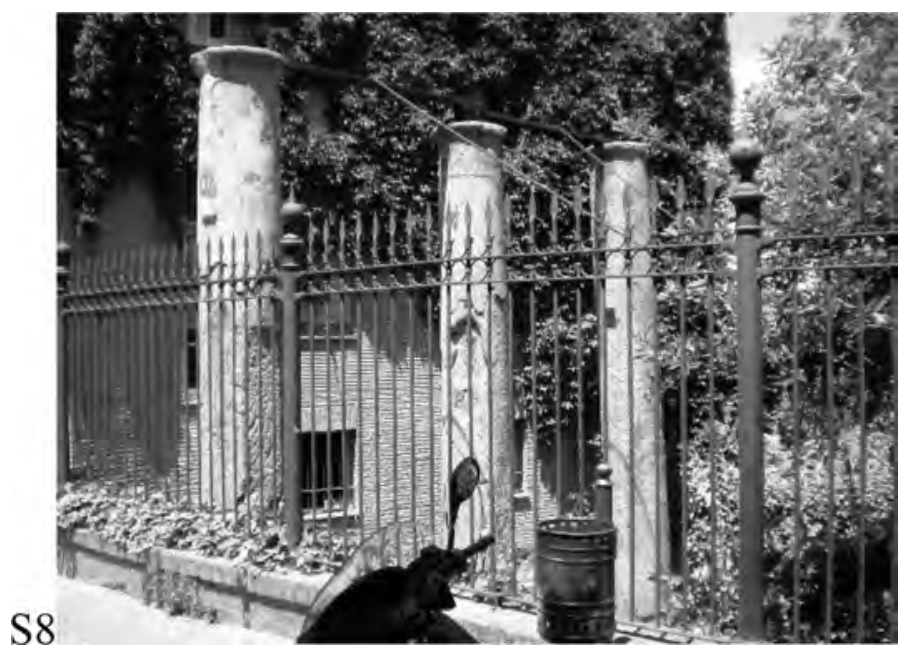

\section{Síntesis interpretativa}

Avanzar una síntesis interpretativa a nivel arquitectónico con la entidad de los restos conocidos es poco menos que una temeridad. Tan sólo hay que ver algunos repertorios de edificios de otras zonas del Mediterráneo, como Jordania (Michel 2001), Norte de África (Duval 1971; 1973), Italia (De Blaauw 2010), Francia (Heijmans-Guyon 2006) e, incluso, Abjasia (Kroushkova 2006), y nos damos cuenta hasta qué punto la situación bética puede calificarse de incipiente. Si lo comparamos con los trabajos de otros colegas de la Península, ya sea a nivel de ciudades (como Tarragona, Valencia o Mértola) o de regiones (como Extremadura o La Mancha), la balanza sigue siendo francamente desfavorable para nuestro ámbito de estudio.

Sin embargo, pensamos que, frente a esta realidad evidente, tampoco hay que imponer una interpretación negativa de lo existente, más bien, todo lo contrario, ya que los avances son muchos desde aquellos tiempos (más superados que lejanos) de los compendios con voluntad de manual (Schlunk; Hauschild 1978) o los análisis un tanto superficiales y parciales (Godoy 1995).

Hoy sabemos que los materiales usados para las edificaciones van desde la sillería hasta la mampostería, pasando por los opera mixta y las soluciones más o 
menos locales, así como por la reutilización masiva de elementos altoimperiales en época tardía. Somos capaces de reconocer determinados tipos de ejecución de obra que son similares en todo el Imperio, y también somos capaces de saber qué tipo de edilicia es común en todos los territorios estudiados y cuál no lo es. Ya podemos hablar con cierta propiedad de tipos de edificios, como iglesias rurales o martyria, y tenemos la posibilidad de plantear hipótesis sobre conjuntos edilicios de envergadura, como los episcopia o los monasterios. Incluso conocemos cómo se mantiene la red de alcantarillado o como se van ocupando calles y pórticos, algunos de forma tan espectacular como los del Astigi, que nos ayudará sin duda a entender, mucho mejor, el mundo funerario y la transformación del centro de las ciudades. Pero, sobre todo, pensamos que este recorrido por la gran arquitectura tardoantigua de la Bética Occidental deja varias ideas-clave planteadas, con vistas a desarrollarse a partir de ahora como líneas de investigación futuras.

No se puede establecer un línea evolutiva o cronológica de tipos de edilicia. Hay una gran variedad, y entre los siglos iv y viII d.C. tenemos proyectos arquitectónicos perfectamente llevados a cabo y de gran envergadura, con sillería u opera mixta muy bien ejecutados, que denotan una importante planificación de medios y ejecución. Igualmente, entre el iv y el viII d.C. contamos con sistemas edilicios que se adaptan perfectamente a la economía de medios, usando mamposterías y morteros muy pobres. No se puede decir que se evolucione desde una gran arquitectura de sillería hacia una albañilería de más o menos envergadura, porque ésta aparece intermitentemente. El único paramento claramente adscrito a una época es el que reutiliza grandes sillares de época romana calzados con cascote, y que en aquellos casos donde se ha documentado se adscribiría al siglo $\mathrm{v}$ d.C.

Los grandes complejos edilicios analizados son, todos, religiosos. No hay grandes complejos arquitectónicos civiles detectados. El único que se plantea abiertamente en la bibliografía (vid. C11) es, cuando menos, muy dudoso, y difícilmente comprensible con lo publicado hasta ahora. Gran parte de los proyectos arquitectónicos religiosos o funerarios se materializan con planta basilical, ya sea con ábside semicircular o cuadrangular, y que se distribuyen a lo largo de todo el periodo estudiado. Aunque existe una llamativa cantidad de edificios de planta central (ya sea cruciforme o poliabsidados) de forma similar a lo que ocurre en Cataluña o el litoral levantino, y que son utilizados tanto para iglesias como para mausoleos. La presencia de grandes edificios funerarios anexos (o junto) a las iglesias es bastante común, y tanto en ámbito rural como en la periferia urbana. Curiosamente, mausoleos y baptisterios comparten características comunes a nivel de edificios y concepción del programa arquitectónico, no encontrándonos baptisterios en edificios de planta central, como es muy normal en Italia (Gandolfi 2001) o Francia (Guyon 2000). En cuanto a su ubicación, los que tenemos constatados con seguridad respecto a sus iglesias se colocan a los pies de las mismas. 
Hay evidentes concomitancias entre el grupo de iglesias béticas occidentales y el hallado en Baleares (Alcaide 2011), especialmente en lo que se refiere a las iglesias de planta rectangular y ábsides inscritos. Pero, junto a ésta, está surgiendo una arquitectura monumental urbana, asociada a las grandes capitales occidentales de la Bética (Corduba, Hispalis, Astigi), que en nada deben envidiar a los grandes conjuntos urbanos y suburbanos mejor conocidos del Mediterráneo Occidental. Y aunque los niveles de destrucción son muy elevados, esta mejor definición de los grandes conjuntos arquitectónicos béticos nos permitirá, como veremos más adelante, afrontar el estudio de la topografía urbana de nuestras ciudades de una forma comprensible.

Queda mucho camino por recorrer, pero creemos haber asentado las bases para una adecuada contextualización de lo ya existente en su entorno hispano y mediterráneo, con la certeza de que nuevos descubrimientos e investigaciones podrán perfilar mejor la etapa más desconocida de nuestra Historia y Arqueología. 
VETERA CHRISTIANA MONUMENTA IN BAETICA. Hacia una sistematización de la arquitectura de época tardoantigua en la parte occidental de la provincia

\section{Bibliografía}

ALCAIDE GONZÁLEZ, S. (2011) Arquitectura cristiana balear en la Antigüedad Tardía (siglos $V-X$ d.C.). Tesis Doctoral Inédita. Tarragona.

ARBEITER, A. (2003) Iglesia de San Miguel de los Fresnos. Fregenal de la Sierra. In: Mateos e Caballero (Ed.) Repertorio de Arquitectura Cristiana en Extremadura. Época Tardoantigua y Altomedieval. Madrid, p. 49-52.

(2010a) ¿Primitivas sedes episcopales hispánicas en los suburbia? La problemática de cara a las usanzas en el ámbito mediterráneo occidental. In: Vaquerizo (ed.): Las áreas suburbanas en la ciudad histórica. Topografía, usos, función. Córdoba, p. 413-434.

(2010b) La llamada a la oración y al servicio religioso. Campanas y campanarios de los cristianos hipánicos anteriores al Románico. Bol. Arqueol. Medieval 14, p. 21-53.

ARCE, J. (1997) Emperadores, palacios y villae. (A propósito de la villa romana de Cercadilla, Córdoba). Antiquité Tardive 5, p. 293-302.

BARRAGÁN VALENCIA, M. C. (2010a) La necrópolis tardoantigua de la Carretera de Carmona (Hispalis). Sevilla.

BENDALA, M. e NEGUERUELA, I. (1980) Baptisterio paleocristiano y visigodo en los reales alcázares de Sevilla. Noticiario Arqueológico Hispánico 10, p. 335-380.

BERTACCHI, L. e LUIGIANO, F. (2003) Nuova pianta archeologica di Aquileia. Aquileia.

BERTELLI, G. (2010) Edilizia di culto cristiano a Napoli, nell'Italia meridionale e insulare dal iv al viı secolo. In: De Blaauw (ed.): Storia Dell'Architettura Italiana: Da Costantino a Carlo Magno. Roma, p. 190-227.

BLANCO FREIJEIRO, A. (1989) Historia de Sevilla: la ciudad antigua (de la Prehistoria a los visigodos). 3a ed. Vol. 79. Sevilla.

BOTELLA ORTEGA, D. e SÁNCHEZ VELASCO, J. (2008) La Basílica de Coracho. Lucena.

BRENK, B. (2005) Architettura e immagini del sacro nella tarda antichità. Spoleto.

CANTINO WATHAGIN, G. (1989) Schede. In: Duval (ed.): Actes du XIème Congrés International d'Archéologie Chrétienne (Lyon, Grenoble-Aosta, 1986), Roma, p. 89-229.

CHAVARRÍA, A. (2010) Suburbio, iglesias y obispos. Sobre la errónea ubicación de algunos complejos episcopales en la Hispania tardoantigua. 
In: Vaquerizo (Ed.) Las áreas suburbanas en la ciudad histórica. Topografía, usos, función. Córdoba, p. 434-454.

COSENTINO, A. (2001) Il fuoco sul Giordano, il cero pasquale, la columna del battistero lateranense. In: Gandolfi (Ed.). L'edificio battesimale in Italia : aspetti e problema. Atti dell'VIII Congresso nazionale di archeologia cristiana: Genova, Sarzana, Albenga, Finale Ligure, Ventimiglia. Bordighera, p. 521-540.

DE BLAAUW, S. (2004) Il Patriarchio, la basilica lateranense e la liturgia. $M E-$ FRA 116, p. 161-172.

DIARTE BLASCO, P. (2012) La configuración urbana de la Hispania tardoantigua. Oxford (BAR IS 2429).

DUVAL, N. (1973) Les églises africaines a deux absides. Recherches archéologiques sur la liturgie chrétienne en Afrique du Nord, II: Inventaire des monuments. Interprétation. Paris.

(1984) L'architecture religieuse de Tsaritchin Grad dans le cadre de l'Illyricum oriental au VIe siècle. In: Villes et peuplement dans l'Illyricum protobyzantin. Actes du colloque de Rome. Roma, p. 399-481.

(1989) Actes du XIe congrès international d'archéologie chrétienne. Lyon, Vienne, Grenoble, Genève, Aoste. Lyon.

(2000) Les relations entre l'Afrique et l'Espagne dans le domaine liturgique: existe-t-il une explication commune pour les contre-absides et contre-choeurs? RAC 76, p. 429-476.

FERGUSON, E. (2009) Baptism in the Early Church. Michigan-Cambridge.

FIOCCHI NICOLAI, V. (2001) Battisteri e chiese rurali (IV-VII secolo). In: Gandolfi (Ed.). L'edificio battesimale in Italia : aspetti e problema. Atti dell'VIII Congresso nazionale di archeologia cristiana: Genova, Sarzana, Albenga, Finale Ligure, Ventimiglia. Bordighera, p. 303-384.

GANDOLFI, D. (Ed.) (2001) L'edificio battesimale in Italia : aspetti e problema. Atti dell'VIII Congresso nazionale di archeologia cristiana: Genova, Sarzana, Albenga, Finale Ligure, Ventimiglia, 21-26 settembre 1998. Bordighera.

GARCÍA LLINARES, G.; MORO GARCÍA, A.; TUSET BERTRÁN, F. (2009) La Seu episcopal d'Egara. Arqueologia d'un conjunt cristià del segle IV al LX. Tarragona.

GARCÍA VARGAS, E. (2012) La Sevilla tardoantigua. Diez años después. (2000-2010). In: Beltrán Fortes, Rodríguez Gutierrez (Eds.): Hispaniae Urbes. Investigaciones arqueológicas en ciudades históricas. Sevilla, p. 881-925. 
VETERA CHRISTIANA MONUMENTA IN BAETICA. Hacia una sistematización de la arquitectura de época tardoantigua en la parte occidental de la provincia

GODOY, C. (1989) Baptisterios hispánicos (siglos iv al viII), Arqueología y liturgia, In: Duval (Ed.) Actes du XIème Congrés International d’Archéologie Chrétienne. Roma, p. 607-634.

(1995) Arqueología y Liturgia. Iglesias hispánicas (siglos IV al VIII). Barcelona.

GRABAR, A. (1946) Martyrium. Recherches sur le culte des reliques et l'Art Chrétien Antique. Limoges.

GURT ESPARRAGUERA, J. M.; SÁNCHEZ RAMOS, I. (2008) Topografía cristiana en Hispania durante los siglos v y vi. Zona Arqueológica 11, 2008, p. 320-345.

(2010) Espacios funerarios y espacios sacros en la ciudad tardoantigua. La situación en Hispania. In: García (Ed.) Espacios urbanos en el occidente mediterráneo (s. VI-VIII), p. 15-28.

(2011) Episcopal groups in Hispania. Oxford Journal of Archaeology, 30, p. 273-298;

GUYON, J. (2000) Les premiers baptistères des Gaules (IVe-VIIIe siècles). Roma.

GUYON,J. (2006) Émergence et affirmation d'une topographie chrétienne dans les villes de la Gaule meridional. Gallia 63, p. 85-110.

HIDALGO PRIETO, R. (2003) En torno a la imagen urbana de Italica. Romula 2, p. 89-126

(2005) Algunas cuestiones sobre la Corduba de la Antigüedad Tardía. In: Gurt i Esparraguera, Ribera i Lacomba (dir.) Les ciutats tardoantigues d'Hispania: cristianización i topografía. VI Reunió d'arqueologia cristiana Hispànica. Barcelona.

JÄGGI, C. (2010) Edilizia di culto cristiano a Ravenna. In: De Blaauw (ed.) Storia Dell' Architettura Italiana: Da Constantino a Carlo Magno. Roma, p. 146-189.

KHROUSHKOVA L. (2006) Les monuments chrétiens de la côte orientale de la Mer Noire. Abkhazie (IVe-XIVe siècles). Brepols.

KINNEY, D. (2010) Edilizia di culto cristiano a Roma e in Italia centrale dalla metà del Iv al vir secolo. In: De Blaauw (ed.) Storia Dell' Architettura Italiana: Da Costantino a Carlo Magno. Roma, p. 54-97.

KRAUTHEIMER, R. (1996) Arquitectura Paleocristiana y Bizantina. Madrid.

(2002) Tre capitali cristiane. Topografia e politica. Milán.

KULIKOWSKI, M. (2005) Later Roman Spain and its Cities, Baltimore.

LIVERANI, P. (2004) L'area lateranense in età tardoantica e le origini del Patriarchio, MEFRA 116, p.17-49. 
LÓPEZ VILAR, J. (2006) Les basíliques paleocristianes del suburbi occidental de Tarraco. El temple septentrional i el complex martirial de Sant Fructuós. Tarragona.

MARTÍNEZ TEJERA, A.M. (2007) “El hábitat 'cenobítico’ en Hispania: organización y dependencias de un espacio elitista en la Antigüedad Tardía y la Alta Edad Media (ss. v-x)”. In: López Quiroga; Martínez Tejera; Morin de Pablos (eds.) Monasteria et Territoria. Elites, edilicia y territorio en el Mediterráneo medieval (siglo V-XI). (BAR IS). p. 19-76.

MICHEL, A. (2001) Les églises d'époque byzantine et umayyade de la Jordanie $V$-VIII siècle. Typologie architecturale et aménagements liturgiques. Thurnhout.

MOLINA MAHEDERO, J.A.; VALDIVIESO RAMOS, A. (2007) Aportaciones a la evolución de las murallas de la Córdoba romana a partir de los datos arqueológicos. Romula 6, p. 29-50.

MOLINA MAHEDERO, J.A. (2005) Nuevos datos sobre el lienzo septentrional de la muralla de Córdoba. Romula 4, p. 99-114.

MORENO MARTIN, F.J. (2009) La configuración arquitectónica del monasterio hispano entre la tardoantigüedad y el alto medievo balance historiográfico y nuevas perspectivas. Anales de historia del arte, N. ${ }^{\circ}$ Extra 1, p. 199-218.

NOLLA BRUFAU, J. M. (1993) Ampurias en la Antigüedad tardía. una nueva perspectiva, Archivo Español de Arqueología 66, p. 207-224.

PANI ERMINI, L. (1989) Schede. In: Duval (ed.) Actes du XIème Congrés International d'Archéologie Chrétienne (Lyon, Grenoble-Aosta, 1986), Roma, p. 89-229.

PICCIRILLO, M. (1989): Gruppi episcopali nelle tre Palestine e in Arabia. In: Duval (ed.) Actes du XIe congrès international d'archéologie chrétienne. Volumes I et II. Roma, p. 459-501

PUERTAS TRICAS, R. (1975) Iglesias hispánicas (siglos IV al VIII). Testimonios literarios. Madrid.

RASCÓN MARQUÉS, S.; SÁNCHEZ MONTES, A, L. (2005) Realidades cambiantes: Complutum tardoantiguo. In: Gurt i Esparraguera, Ribera i Lacomba (dir.): Les ciutats tardoantigues d'Hispania: cristianització i topografía. VI Reunió d'arquepologia cristiana Hispànica. Barcelona, p. $499-517$

RIBERA I LACOMBA, A.; ROSELLÓ MESQUIDA, M. (2007) Escultura decorativa de época tardoantigua en Valencia y su entorno. In: Caballero Zoreda; Mateos Cruz (coord.): Escultura decorativa tardorromana y altomedieval en la Peninsula, Madrid, p. 345-366. 
VETERA CHRISTIANA MONUMENTA IN BAETICA. Hacia una sistematización de la arquitectura de época tardoantigua en la parte occidental de la provincia

RIBERA I LACOMBA, A. (2008) La primera topografía cristiana de Valencia (Hispania Carthaginensis). Rivista Archeologia Cristiana 83, p. 377-434.

RISTOW, S. (1998) Frühchristliche Baptisterien. Münster.

RODRIGUEZ HIDALGO, J.M.; KEAY, S.; JORDAN, D. e CREGHTON, J. (1999) La Italica de Adriano. Resultados de las prospecciones arqueológicas de 1991 y 1993. Archivo Español de Arqueologia 72, p. 73-78.

ROSELLÓ MESQUIDA, M. (2005) El territorium de Valentia a l' Antiguitat Tardana. In: Gurt i Esparraguera, Ribera i Lacomba (dir.): Les ciutats tardoantigues d'Hispania: cristianització i topografía. VI Reunió d'arquepologia cristiana Hispànica. Barcelona, p. 279-304.

SAMI, D. (2010) Changing Beliefs: the Transition from Pagan to Christian Towns in Late Antique Sicily. In: Sami e Speed (eds.): Debating Urbanism: Within and Beyond the Walls, AD 300-700. Leicester, p. 213-237.

SÁNCHEZ RAMOS, I. (2007) La cristianización de las necrópolis de Corduba: Fuentes escritas y testimonios arqueológicos. Archivo Español de Arqueologia 80, p. 191-206.

(2009) Arquitectura sacra de época tardía en Hispalis. Algunas reflexiones. Archivo Español de Arqueología 82, p. 255-274.

(2010) Las ciudades de la Bética en la Antigüedad tardía. Antiquité Tardive 18, p. 243-276.

SASTRE DE DIEGO, I. (2009) El altar en la Arquitectura Cristiana Hispánica. Siglos $V$-X. Estudio Arqueológico. Tesis Doctoral inédita.

(2010): Los primeros edificios cristianos de Extremadura. Sus espacios y elementos litúrgicos. Caelum in Terra. Mérida.

SCHLUNK, H.; HAUSCHILD, T. (1978) Hispania Antiqua. Die Denkmäler der frubchristlichen und westgotischen Zeit. Mainz am Rhein.

TARRADELLAS COROMINAS, M. C. (2000) Topografía Urbana de Sevilla durante la Antigüedad Tardía, V Reunió d'Arqueología Cristiana Hispànica. Barcelona, p. 279-290.

TESTINI, P.; CANTINO WATAGHIN, G.; PANI ERMINI, L. (1989): La Cattedrale in Italia. In: Duval (ed.) Actes du XIe congrès international d'archéologie chrétienne. Roma, p. 5-229 [fichas de cada una de las ciudades italianas en p. 89 - 229].

VARALIS, Y.D. (1999) Deux églises à chœur tréflé de l'Illyricum oriental Observations sur leur type architectural. Bulletin de Correspondance Hellénique 123, p. 195-225. 
VERDUGO SANTOS, J. (2003) El cristianismo en Itálica: Fuentes, tradiciones, y testimonios arqueológicos. In: Bosch Jimenez et al. (coords): Santos, Obispos y reliquias, Alcalá de Henares, p. 353-389.

VIZCAÍNO SÁNCHEZ, J. (2009) La presencia bizantina en Hispania (siglos VI-VII): la documentación arqueológica. Murcia.

WOLFRAM, M. (2012) La christianisation du monde rural dans le Sud de la Lusitanie. Archéologie-Architecture-Epigraphie. Tesis Doctoral Inédita. Universidad de la Sorbona, París. 
VETERA CHRISTIANA MONUMENTA IN BAETICA. Hacia una sistematización de la arquitectura de época tardoantigua en la parte occidental de la provincia

\section{APÉNDICE CARTOGRÁFICO. MAPAS Y PLANOS.}

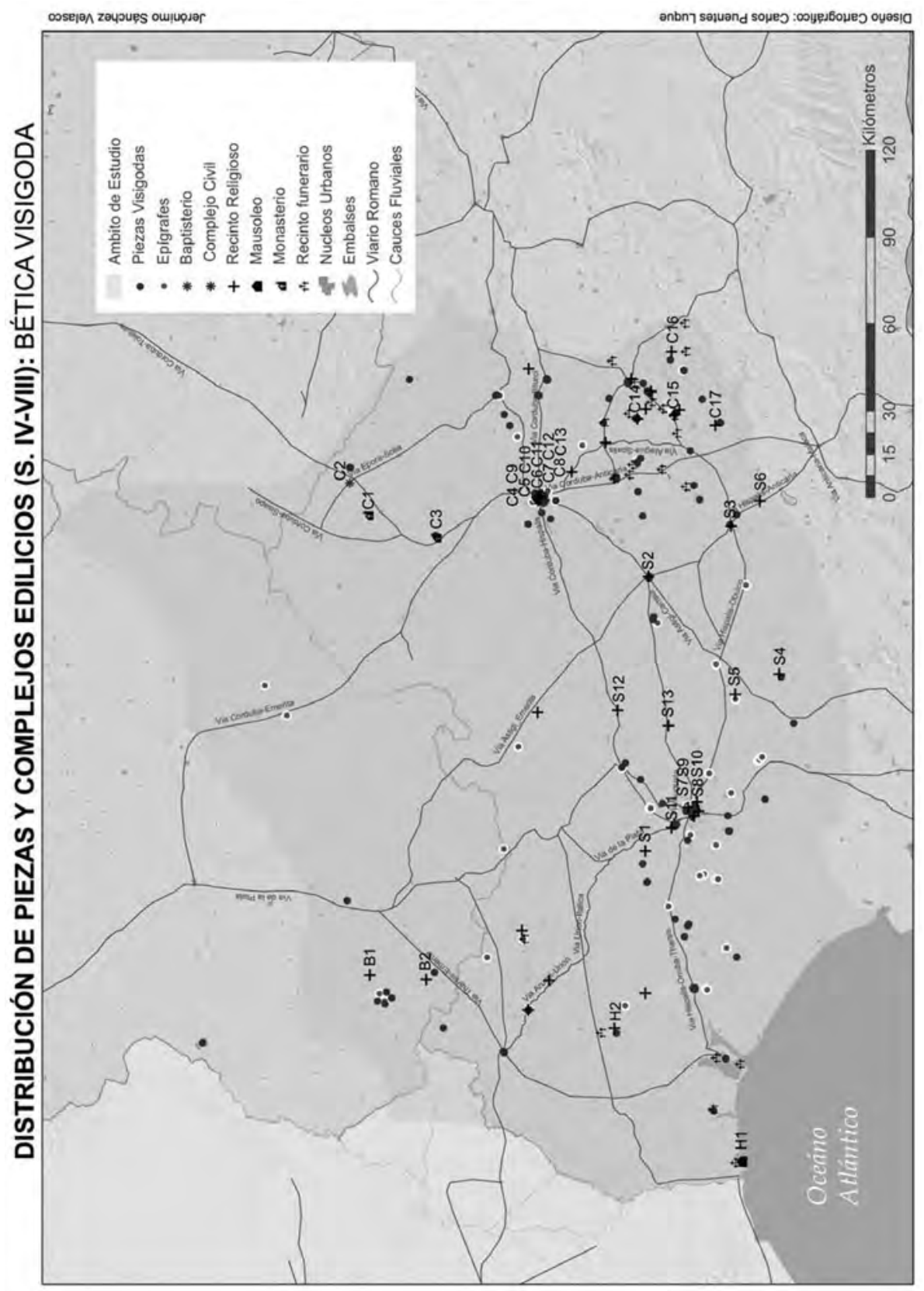

Mapa 1 - Complejos edilicios de la Bética Occidental. 
Jerónimo Sanchez Velasco

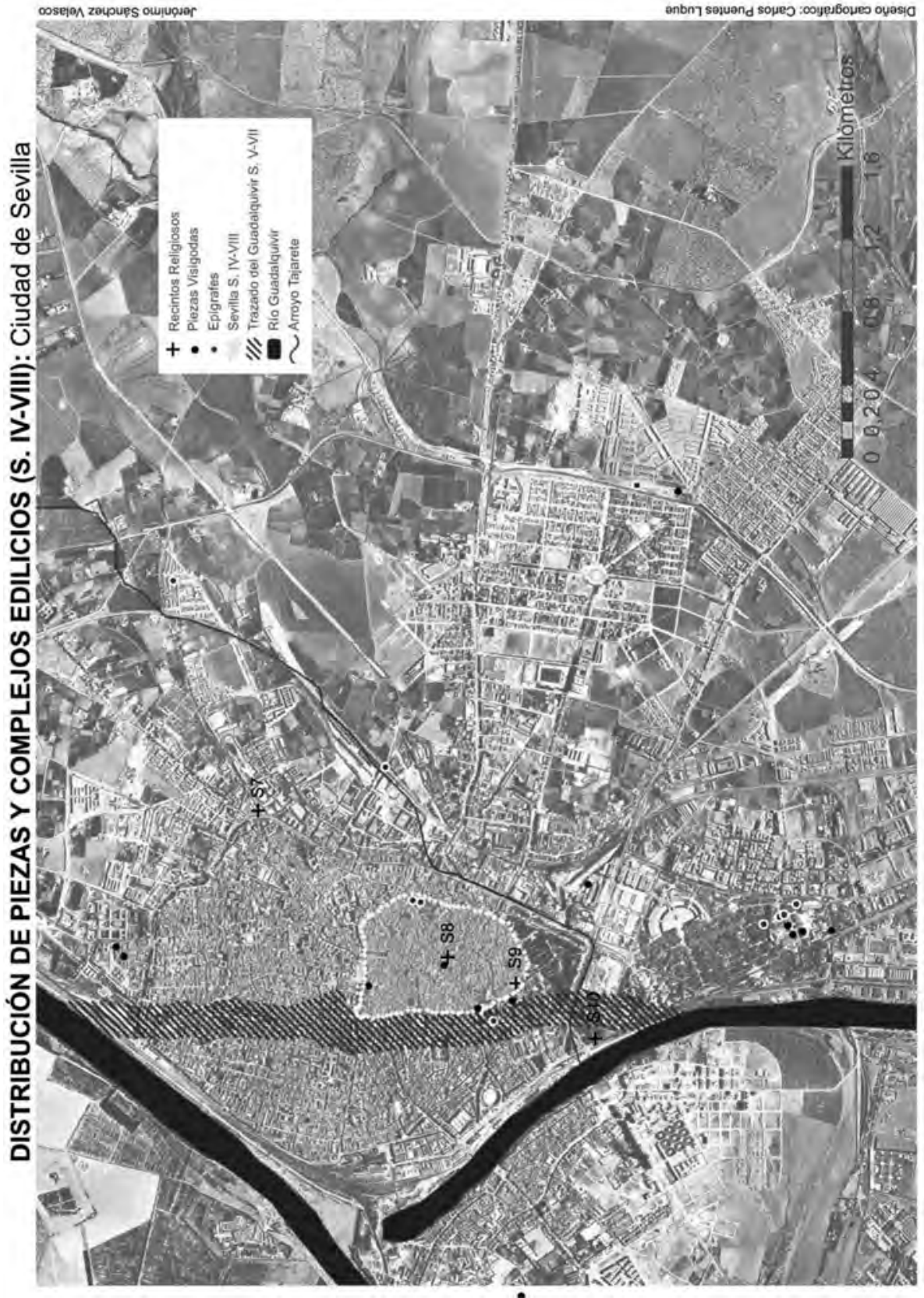

Plano 1 - Complejos edilicios de la Sevilla tardoantigua. 
VETERA CHRISTIANA MONUMENTA IN BAETICA. Hacia una sistematización de la arquitectura de época tardoantigua en la parte occidental de la provincia

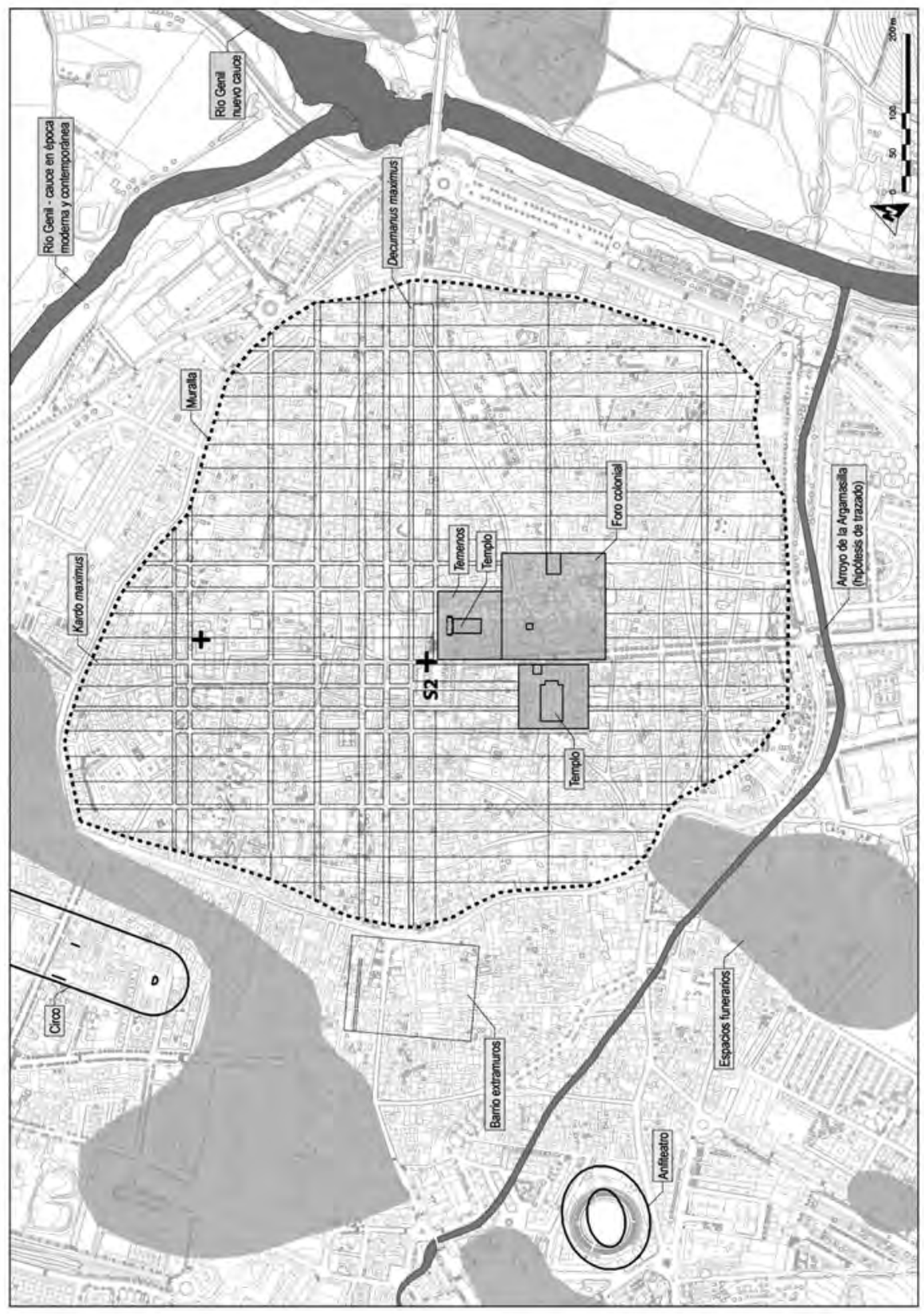

Plano 2 - Complejos edilicios de la Écija tardoantigua. 
Jerónimo Sanchez Velasco

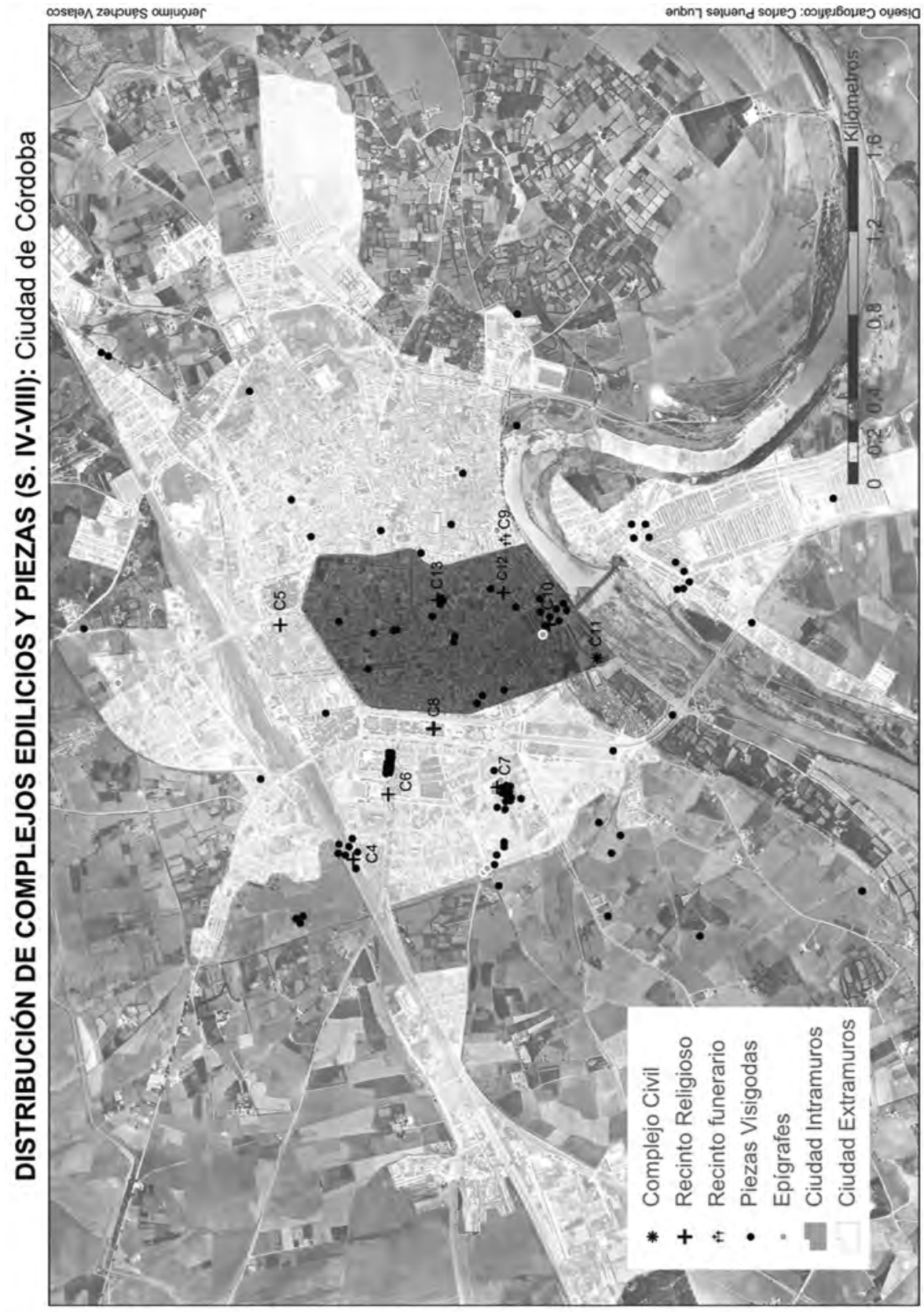

Plano 3 - Complejos edilicios de la Córdoba tardoantigua. 